\title{
Comparing bacterial membrane interactions and antimicrobial activity of porcine lactoferricin-derived peptides
}

\author{
F. F. Han, Y. H. Gao, C. Luan, Y. G. Xie, Y. F. Liu, and Y. Z. Wang ${ }^{1}$ \\ Key Laboratory of Molecular Animal Nutrition, Ministry of Agriculture and Key Laboratory of Animal Feed and Nutrition of Zhejiang Province, \\ Institute of Feed Science, Zhejiang University, Hangzhou 310058, China
}

\begin{abstract}
Antibiotic treatment for microbial infections is under scrutiny due to increasing resistance to conventional antibiotics, warranting discovery of new classes of antibiotic agents. Antimicrobial peptides are part of the innate defense system found in nearly all organisms and possess bactericidal mechanisms that make it more difficult for bacteria to develop resistance. Porcine lactoferricin (LFP-20) is an antimicrobial peptide located in the $\mathrm{N}$ terminus of lactoferrin (LF). To develop novel cell-selective antimicrobial peptides with improved antimicrobial specificity compared with LFP-20, analogs LF2A LF-2, LF-4, and LF-6 were substituted with Ala, Ser, or Trp residues at different positions in the molecule. Analogs displayed a 2- to 16-fold higher antimicrobial activity than LFP-20, but were hemolytic at $64 \mu \mathrm{g} / \mathrm{mL}$. Additionally, LFP-20, LF2A, LF-2, and LF-4 exhibited lower cytotoxicity against human peripheral blood mononuclear cells than LF-6 at concentrations of 25 to $100 \mu \mathrm{g} / \mathrm{mL}$. To better understand the antibacterial mechanisms of LFP-20 and its analogs we examined their effect on the cytoplasmic membrane of Escherichia coli. The LFP-20 was not effective in depolarizing cytoplasmic membranes, whereas the other 3 analogs gradually dissipated the membrane potential of E. coli. Membrane potential increased with minimal inhibitory concentrations changes, demonstrating a correlation between bactericidal activity and membrane depolarization. Analogs were more efficient than LFP-20 in displacing lipopolysaccharide-bound dansylpolymyxin $\mathrm{B}$, which also rapidly increased 1-N-phenylnaphthylamine uptake and release of cytoplasmic $\beta$-galactosidase by increasing the permeability of the outer and inner membranes of E. coli. The 3 analogs caused an increased potential for calcein leakage from negatively charged lipid vesicles at high concentrations. Collectively, these results suggest that the first targets of LF-2, LF-4, and LF-6 in E. coli are cytoplasmic mem-
\end{abstract}

Received August 30, 2012.

Accepted February 11, 2013.

${ }^{1}$ Corresponding author: yzwang@zju.edu.cn branes. The 3 analogs exhibited lethal effects based on their abilities to disrupt membranes and permit transit of large intracellular components, such as calcein.

Key words: porcine lactoferricin, antimicrobial activity, mechanism, cytoplasmic membrane

\section{INTRODUCTION}

Antibiotics represent some of the major scientific and medical advances of the 20th century. The discovery and development of conventional antibiotics, which are primarily based on bacteria- or fungi-generated antimicrobial compounds, has led to dramatic improvements in the ability to treat infectious diseases and significant increases in animal production. Although antibiotic therapy remains the first choice for treating microbial infections in humans and animals, increasing rates of antibiotic resistance is a growing public health concern (Gordon et al., 2005; Sang and Blecha, 2008). This has driven the search for new antimicrobials that are broadly effective and less likely to induce antimicrobial resistance. Thus, one potentially useful but underdeveloped class of antibiotic agents is the antimicrobial peptides (AMP; Rathinakumar et al., 2009).

Antimicrobial peptides generally contain 12 to 100 AA residues, have a net positive charge, and have an amphipathic structure that facilitates interaction with negatively charged microbial membranes or other cellular targets (Yeaman et al., 2007; Sang and Blecha, 2008). Compared with conventional antibiotics, AMP often exert broad spectrum activity against microorganisms, including bacteria, fungi, parasites, enveloped viruses, and even some cancer cells. Additionally, conventional antibiotics generally target a metabolic enzyme and may selectively induce resistance in microorganisms, whereas AMP kill microbes primarily through membrane-targeting pore-forming mechanisms, which are inherently more difficult for microbes to circumvent by developing resistance (Hancock and Sahl, 2006; Sang and Blecha, 2008; Fan et al., 2011).

Porcine lactoferricin (LFP-20) is one of the 20 amino acid AMP identified in the $\mathrm{N}$ terminus of the lactoferrin ( $\mathbf{L F})$, a member of the porcine LF family. It 
exhibits moderate antimicrobial activity against Escherichia coli, Staphylococcus aureus, and Candida albicans through a mechanism directly leading to cell wall disruption and outer membrane breakdown (Chen et al., 2006a). A limitation of AMP for use in therapeutics is that many possess cytotoxic and hemolytic properties, whereas others have relatively weak antimicrobial activity. Therefore, several studies have focused on designing cell-selective peptides with strong antimicrobial activity but no toxicity against mammalian cells for use as antibiotic agents (Oren et al., 1997; Chen et al., 2005; Wang et al., 2009). In our previous study, we found that LFP-20 does not exhibit hemolysis and has very low cytotoxicity to eukaryotic cells (unpublished data). This study focuses on identifying key AA in the LFP-20 sequence and enhancing the activity of various LFP-20 peptide analogs using AA substitutions and activity assays. We also developed a plausible bactericidal mechanism by measuring depolarization of the cytoplasmic membrane potential of intact E. coli cells and their ability to cause leakage of a fluorescent dye from lipid vesicles to mimic bacterial membranes.

\section{MATERIALS AND METHODS}

\section{Peptide Synthesis}

Peptides were synthesized by standard solid-phase procedures with 9-fluorenyl- methoxycarbonyl using an Apex 396 peptide synthesizer (Aapptec, Louisville, KY). Ninety-five percent purity of synthetic peptides was achieved and verified using Agilent 1200 Series HPLC (Agilent Technologies, Santa Clara, CA) and a Thermo Finnigan LCQ ion trap mass spectrometer (Thermo Finnigan, San Jose, CA). A concentrated stock solution of each test compound was prepared in endotoxin-free water and stored at $-80^{\circ} \mathrm{C}$ until use.

\section{Bacterial Strains and Reagents}

Escherichia coli ATCC25922, E. coli K88, E. coli AG1, E. coli JM109, E. coli DH 5a, E. coli UB1005, E. coli ML-35, Staphylococcus epidermidis C621, Staphylococcus aureus ATCC25923, Pseudomonas aeruginosa H103, P. aeruginosa PA14, Salmonella choleraesuis CMCC50020, and Salmonella typhimurium CMCC50013 were included in this study. Escherichia coli AG1, E. coli UB1005, E. coli ML-35, Staph. epidermidis C621, P. aeruginosa H103, and P. aeruginosa PA14 were donated by R. E. W. Hancock (Centre for Microbial Diseases and Immunity Research, The University of British Columbia, Vancouver, Canada). All strains were grown in Mueller Hinton broth (MHB; Difco Laboratories, Detroit, MI) at $37^{\circ} \mathrm{C}$ unless otherwise noted. The fluorescent dyes, $\operatorname{diSC}_{3} 5$ and dansyl-polymyxin $\mathrm{B}$, were purchased from Molecular Probes (Eugene, OR); O-nitrophenyl $\beta$-D-galactoside (ONPG), N-phenyl-1-naphthylamine $(\mathbf{N P N})$, and calcein were obtained from SigmaAldrich, Inc. (St. Louis, MO). Zwitterionic phospholipid, 1-palmitoyl-2-oleoyl-sn-glycero-3-phosphocholine (POPC); anionic phospholipid, 1-palmitoyl-2-oleoylsn-glycero-3-phospho-rac-(1-glycerol) (POPG), 1-oleoyl-2-hydroxy-sn-glycero-3-phospho-(1'-rac-glycerol), cardiolipin (CL), and 1-palmitoyl-2-oleoyl-sn-glycero3-phosphoethanolamine (PE) were purchased from Avanti Polar Lipids Inc. (Alabaster, AL). All other reagents were of the highest grade commercially available.

\section{Cell Isolation}

Fresh human venous blood from healthy volunteers was collected in vacutainer collection tubes containing sodium heparin as an anticoagulant (BD Biosciences, Franklin Lakes, NJ) in accordance with Zhejiang University ethical approval and guidelines. The blood was diluted in an equal volume of complete RPMI 1640 medium supplemented with $10 \%$ (vol/vol) heatinactivated fetal bovine serum, $2 \mathrm{~m} M$ L-glutamine, and $1 \mathrm{~m} M$ sodium pyruvate (Invitrogen, Carlsbad, CA), and separated using centrifugation over a Ficoll-Paque Premium (GE Healthcare Bio-sciences Corp., Uppsala, Sweden) density gradient. Mononuclear cells and erythrocytes were collected and washed twice in RPMI 1640 medium. The number of peripheral blood mononuclear cells (PBMC) was determined using trypan blue exclusion. The PBMC were seeded into 96-well tissue culture plates (BD Biosciences) at $1 \times 10^{6}$ cells/ $\mathrm{mL}$ at $37^{\circ} \mathrm{C}$ in $5 \% \mathrm{CO}_{2}$. All experiments using human PBMC or erythrocytes involved at least 4 biological replicates.

\section{MIC Determination}

Minimal inhibitory concentrations of the peptides were measured using a modified broth microdilution method in MHB (Wiegand et al., 2008). Briefly, cells were grown overnight at $37^{\circ} \mathrm{C}$ in $\mathrm{MHB}$ medium and were diluted in the same medium to give $1 \times 10^{6} \mathrm{cfu} /$ $\mathrm{mL}$. The assay was performed in sterile 96-well polypropylene microtiter plates (Costar, Cambridge, MA). Serial dilutions of the peptides at 10-fold of the desired final concentration were added to each well of the microtiter plates in a volume of $10 \mu \mathrm{L}$, followed by addition of $90 \mu \mathrm{L}$ of diluted bacteria. Plates were incubated at $37^{\circ} \mathrm{C}$ for $18 \mathrm{~h}$, and MIC were determined as the lowest peptide concentration at which no bacterial growth was observed. 


\section{Measurement of Hemolytic Activity}

Hemolytic activity of the peptides was assessed based on hemoglobin release from human erythrocytes following cell lysis (Chen et al., 2006b). The assay was carried out in 96-well polypropylene microtiter plates. Isolated erythrocytes were washed 3 times in sterile phosphate buffer $\left(100 \mathrm{~m} M \mathrm{NaCl}, 80 \mathrm{~m} M \mathrm{Na}_{2} \mathrm{HPO}_{4}\right.$, $20 \mathrm{mM} \mathrm{NaH} \mathrm{PO}_{4}, \mathrm{pH}$ 7.4) and centrifuged at $500 \times$ $g$ for $10 \mathrm{~min}$. Two-fold serial dilutions (ranging from $4-128 \mu \mathrm{g} / \mathrm{mL}$ ) of peptide samples were added to $1 \%$ human erythrocytes in phosphate buffer and the reaction mixtures were incubated at $37^{\circ} \mathrm{C}$ under $5 \% \mathrm{CO}_{2}$ for $18 \mathrm{~h}$ in microtiter plates. Aliquots were withdrawn from the hemolysis assays and unlysed erythrocytes were removed by centrifugation $(500 \times g$ for $5 \mathrm{~min}$ ). Hemoglobin release was monitored chromogenically at 414 and $546 \mathrm{~nm}$ using an ELISA plate reader. The control for no release of hemoglobin was a sample of $1 \%$ erythrocytes without any peptide added. Because erythrocytes were in an isotonic medium, no detectable release $(<1 \%$ of that released upon complete hemolysis) of hemoglobin was observed from this control during the assay. Hemolysis of erythrocytes induced by $1 \%$ (vol/vol) Triton X-100 (Sigma-Aldrich) was taken as $100 \%$. All experiments were repeated at least 4 times.

\section{Cell Viability Assay}

The inhibition effects of 6 peptides on PBMC were evaluated using the cell proliferation reagent WST-1 (Roche Applied Science, Mannheim, Germany). In 96-well plates, PBMC $\left(1 \times 10^{6}\right.$ cells/well $)$ were resuspended in RPMI 1640 medium supplemented with 10\% heat inactivated fetal bovine serum and incubated at $37^{\circ} \mathrm{C}$ in $5 \% \mathrm{CO}_{2}$ for $2 \mathrm{~h}$. Next, various concentrations of peptides $(12.5-200 \mu \mathrm{g} / \mathrm{mL})$ were added to a final volume of $100 \mu \mathrm{L}$. After 18 -h incubation at $37^{\circ} \mathrm{C}$ under $5 \% \mathrm{CO}_{2}, 10 \mu \mathrm{L}$ of WST-1 reagent was added to each well and samples were further incubated for $60 \mathrm{~min}$. Absorbance of the colored formazan was measured using an automated microplate reader (Lambda E, MWG Biotech, Ebersberg, Germany) at a wavelength of 450 $\mathrm{nm}$, using $900 \mathrm{~nm}$ as a reference wavelength. The mean absorbance of control wells (cells without peptides) represented $100 \%$ cell viability.

\section{Lactate Dehydrogenase Release Assay for Cytotoxicity}

To detect direct peptide-induced cell lysis, we performed lactate dehydrogenase (LDH) release assays (Roche Applied Science) according to the manufacturer's instructions. The PBMC were seeded in 96-well plates for $2 \mathrm{~h}$ and incubated with various concentrations of peptides for another $18 \mathrm{~h}$ at $37^{\circ} \mathrm{C}$ under $5 \%$ $\mathrm{CO}_{2}$. Cells were treated with $2 \%$ (vol/vol) Triton X-100 for 10 min before running the assay as a positive control for maximum LDH release. Untreated cells served as controls for spontaneous LDH release. Supernatants were removed and centrifuged at $800 \times g$ for $10 \mathrm{~min}$ to remove contaminating cells. Aliquots of test culture supernatants were treated with enzymatic assay reagent for $30 \mathrm{~min}$. Absorbances were subsequently measured in a microtiter plate reader at $490 \mathrm{~nm}$, using $900 \mathrm{~nm}$ as a reference wavelength. Specific LDH release was calculated using the following formula: \% LDH release $=100 \times($ Exp-Spo $) /($ Max-Spo $)$, with Exp representing experimental release, Spo representing baseline release, and Max representing maximum LDH release.

\section{Cytoplasmic Membrane Depolarization Assay}

Cytoplasmic membrane depolarization was monitored using the membrane potential-sensitive cyanine dye $\mathrm{DiSC}_{3} 5$, in a Luminescence Spectrometer LS50B (PerkinElmer, Waltham, MA) at room temperature (Wu and Hancock, 1999). Depolarization of the cytoplasmic membrane was determined using the gram-negative mutant bacterium E. coli UB1005. Midlogarithmic phase bacteria cultured in fresh MHB were washed and resuspended in buffer ( $5 \mathrm{~m} M$ of HEPES, $5 \mathrm{~m} M$ of glucose buffer for E. coli, $\mathrm{pH} 7.2$ ) to an optical density at $600 \mathrm{~nm}\left(\mathbf{O D}_{600}\right)$ of 0.05 . The bacterial suspension of $E$. coli UB1005 was incubated with 0.8 $\mu M$ of $\mathrm{DiSC}_{3} 5$ for $1.5 \mathrm{~h}$ (until $\mathrm{DiSC}_{3} 5$ uptake was maximal); subsequently, $200 \mathrm{mM}$ of $\mathrm{KCl}$ was added and cells were cultured for $30 \mathrm{~min}$ to equilibrate cytoplasmic and external $\mathrm{K}^{+}$concentration. Next, a 1-mL aliquot of cell suspension was placed in a 1-cm cuvette, and the desired concentration of peptides was added. Fluorescence was monitored at an excitation wavelength of $622 \mathrm{~nm}$ and an emission wavelength of $670 \mathrm{~nm}$. The maximum increase in fluorescence due to disruption of the cytoplasmic membrane by a specific concentration of peptide was recorded. A blank with only cells and dye was used to subtract the background.

\section{Dansyl-Polymyxin B Displacement Assay}

The relative binding affinity of each peptide for LPS was determined using the dansyl-polymyxin B displacement assay by Moore et al., (1986), with LPS isolated from E. coli UB1005. Liposaccharide was solubilized in $5 \mathrm{~m} M$ of HEPES (pH 7.0) at a final concentration of 3 $\mu \mathrm{g} / \mathrm{mL}$, and then dansyl-polymyxin B was added ( $5 \mu M$ of final concentration). The increase in fluorescence due to binding between these 2 molecules was monitored 
in an LS50B fluorescence spectrophotometer with the excitation monochromator set at $340 \mathrm{~nm}$ and emission at $485 \mathrm{~nm}$. Once fluorescence was stabilized, addition of a given peptide-displaced LPS-bound dansyl-polymyxin B occurred, resulting in a decrease in dansylpolymyxin B fluorescence. Results were expressed as the $\mathrm{I}_{50}$ (peptide concentration causing $50 \%$ reduction of maximal binding) and $I_{\max }$ (percentage of maximal displacement).

\section{Outer Membrane Permeability Assay}

The ability of peptides to permeabilize the outer membrane of $E$. coli UB1005 was determined using the fluorescent probe NPN (Loh et al., 1984). Muller Hinton broth $(10 \mathrm{~mL})$ was inoculated with a single colony of $E$. coli incubated aerobically overnight at $37^{\circ} \mathrm{C}$. Next, $2 \mathrm{~mL}$ of the overnight culture was used to inoculate $50 \mathrm{~mL}$ of $\mathrm{MHB}$ and the cells were grown to mid-logarithmic phase $\left(\mathrm{OD}_{600} 0.4-0.6\right)$. Bacterial cultures were harvested by centrifugation at $1,100 \times$ $g$ for $10 \mathrm{~min}$. Next, cells were washed and resuspended to an $\mathrm{OD}_{600}$ of 0.5 in the buffer, including $5 \mathrm{mM}$ of HEPES (pH 7.0), $5 \mathrm{~m} M$ of glucose, and $5 \mu M$ of carbonyl cyanide-m-chlorophenyl hydrazone. One milliliter of each bacterial suspension was placed in a quartz cuvette with a magnetic stir bar. A stock solution of NPN dissolved in acetone was added to the cuvette to a final concentration of $10 \mu M$, and the fluorescence (baseline) was measured using an LS50B fluorescence spectrophotometer with the excitation monochromator set at $350 \mathrm{~nm}$ and emission to $420 \mathrm{~nm}$. Aliquots containing increasing amounts of peptides or polymixin $\mathrm{B}$ were added to samples of each bacterial suspension and the change in fluorescence was monitored. Increase in fluorescence due to peptide-mediated entry of the hydrophobic fluorophor NPN into the membrane was measured until a stable signal was observed, indicating that additional partitioning of NPN into the membrane had stopped. Control tests were performed to verify that the enhanced fluorescence was due to NPN uptake by bacteria.

\section{Inner Membrane Permeabilization Assay}

Permeabilization of the cytoplasmic inner membranes of $E$. coli ML-35 by peptides was evaluated by following unmasking of cytoplasmic $\beta$-galactosidase activity using extracellular ONPG (Sigma-Aldrich) as the substrate. For these experiments, the $\beta$-galactosidase constitutive, lactose permease-deficient $E$. coli ML-35 strain was exposed to different peptide concentrations (Je and Kim, 2006). Mid-logarithmic phase bacteria grown in MHB were harvested, washed, and resuspended in $10 \mathrm{mM}$ of sodium phosphate buffer ( $\mathrm{pH} 7.5$ ) containing $100 \mathrm{mM}$ of $\mathrm{NaCl}$. Freshly prepared bacteria were always used as soon as possible after resuspension in buffer. The final cell suspension was adjusted to obtain an $\mathrm{OD}_{600}$ of 0.5 . The bacterial suspension $(200 \mu \mathrm{L})$ was pipetted into the wells of a standard microtiter plate followed by addition of $10 \mu \mathrm{L}$ of ONPG $(30 \mathrm{mM})$ to each well. Production of O-nitrophenol over time was measured by monitoring the increase in fluorescence at $415 \mathrm{~nm}$ using a spectrophotometer.

\section{Calcein Leakage Assay}

Large unilamellar vesicles (LUV) composed of PE/ POPG/CL (80: 15: 5), POPC/POPG (3:1), POPC/ POPG (1:1), or highly anionic POPG were prepared by dissolving dried lipids in chloroform, which were dried under a stream of nitrogen followed by $2 \mathrm{~h}$ of vacuum drying. The lipid film was rehydrated in $20 \mathrm{mM}$ of HEPES, $150 \mathrm{mM}$ of $\mathrm{NaCl}$, and $1 \mathrm{mM}$ of EDTA, pH 7.4. To make calcein-encapsulated unilamellar liposomes, the lipid film was rehydrated using $5 \mathrm{~m} M$ of sodium HEPES (pH 7.5), containing $100 \mathrm{~m} M$ of calcein. The liposome suspension was freeze-thawed in liquid nitrogen for 5 cycles and extruded 10 times through 2 stacked polycarbonate filters with a pore size of $100 \mathrm{~nm}$ using the Avanti Mini-Extruder. Untrapped calcein was removed by passing the liposome suspension through a Sephadex G-50 column (Amersham Pharmacia Biotech, Little Chalfont, UK) and eluted using a buffer containing $20 \mathrm{~m} M$ of HEPES, $150 \mathrm{mM}$ of $\mathrm{NaCl}$, and 1 $\mathrm{m} M$ of EDTA, $\mathrm{pH}$ 7.4. This elution buffer and calceinfree unilamellar liposomes were added to adjust final liposome concentrations in calcein leakage experiments.

Leakage of calcein from LUV was monitored by measuring the fluorescence intensity at an excitation wavelength of $490 \mathrm{~nm}$ and emission wavelength of $520 \mathrm{~nm}$ on an LS50B fluorescence spectrophotometer. Peptides were added in fixed concentration steps. The sample was stirred with a magnetic stir bar for a short time immediately after adding peptides to ensure uniform mixing. To determine $100 \%$ leakage of dye, $0.1 \%$ Triton $\mathrm{X}-100$ was added to dissolve the vesicles. The percentage of dye leakage caused by peptides was calculated as follows: dye leakage $(\%)=100 \times\left(\mathrm{F}-\mathrm{F}_{0}\right) /\left(\mathrm{F}_{\mathrm{t}}-\mathrm{F}_{0}\right)$, where $\mathrm{F}$ is the fluorescence intensity achieved by the peptides, and $\mathrm{F}_{0}$ and $\mathrm{F}_{\mathrm{t}}$ are the fluorescence intensities without peptides and with Triton X-100, respectively.

\section{Scanning Electron Microscopy}

Escherichia coli ATCC25922 were grown to midlogarithmic phase in MHB and further diluted in MHB to obtain a final concentration of $2 \times 10^{6} \mathrm{cfu} / \mathrm{mL}$. An 
equal volume of bacterial suspension and peptides were mixed to give a total volume of $1 \mathrm{~mL}$, yielding a final concentration of the MIC of the peptide. The solutions were placed in a water shaker at $37^{\circ} \mathrm{C}$ for $30 \mathrm{~min}$, centrifuged for $10 \mathrm{~min}$ at $1,700 \times g$, and the resulting pellet was used for electron microscopy. Specimens were washed 3 times in the phosphate buffer $(\mathrm{pH}$ 7.0) before the first fixation with $2.5 \%$ glutaraldehyde in phosphate buffer for more than $4 \mathrm{~h}$, then postfixed with $1 \% \mathrm{OsO}_{4}$ in phosphate buffer $\left(100 \mathrm{mM}\right.$ of $\mathrm{NaCl}, 80 \mathrm{mM}$ of $\mathrm{Na}_{2} \mathrm{H}-$ $\mathrm{PO}_{4}, 20 \mathrm{mM}$ of $\mathrm{NaH}_{2} \mathrm{PO}_{4}, \mathrm{pH}$ 7.4) for $1 \mathrm{~h}$ and washed 3 times in phosphate buffer. After double fixation, specimens were first dehydrated using a graded series of ethanol (50, 70, 80, 90, 95, and 100\%) sequentially for $15 \mathrm{~min}$ at each step, they were then transferred to a mixture of alcohol and iso-amyl acetate $(\mathrm{vol} / \mathrm{vol}=1: 1)$ for approximately $30 \mathrm{~min}$, then transferred into pure iso-amyl acetate for approximately $1 \mathrm{~h}$. Specimens were dehydrated using a Hitachi critical point dryer (Model HCP-2, Hitachi, Tokyo, Japan) with liquid $\mathrm{CO}_{2}$. Dehydrated specimens were coated with gold-palladium and observed under 10,000 to $15,000 \times$ magnification in a scanning electron microscope (Philips Model XL30 ESEM, Philips, Amsterdam, the Netherlands)

\section{Transmission Electron Micrographs}

Escherichia coli ATCC25922 were grown in MHB at $37^{\circ} \mathrm{C}$ to mid-logarithmic phase. The bacteria were washed in buffer $\left(100 \mathrm{mM}\right.$ of $\mathrm{NaCl}, 80 \mathrm{mM}$ of $\mathrm{Na}_{2} \mathrm{H}$ $\mathrm{PO}_{4}, 20 \mathrm{~m} M$ of $\mathrm{NaH}_{2} \mathrm{PO}_{4}, \mathrm{pH}$ 7.4) and resuspended in the same buffer. Peptides were incubated with $E$. coli ATCC25922 $\left(2 \times 10^{6} \mathrm{cfu} / \mathrm{mL}\right)$ for $30 \mathrm{~min}$ in a total volume of $1 \mathrm{~mL}$. Specimens were first fixed with $2.5 \%$ glutaraldehyde in phosphate buffer $(\mathrm{pH} 7.0)$ for more than $4 \mathrm{~h}$, washed 3 times in phosphate buffer, then postfixed with $1 \% \mathrm{OsO}_{4}$ in phosphate buffer $(\mathrm{pH} 7.0)$ for $1 \mathrm{~h}$ and washed 3 times in phosphate buffer. Specimens were then dehydrated using a graded series of ethanol (50, $70,80,90,95$, and $100 \%$ ) for approximately $15 \mathrm{~min}$ at each step, then transferred to absolute acetone for 20 min. After dehydration, specimens were placed in a 1:1 mixture of absolute acetone and Spurr's resin mixture for $1 \mathrm{~h}$ at room temperature, and then transferred to 1:3 mixture of absolute acetone and Spurr's resin mixture for $3 \mathrm{~h}$ and to a final Spurr's resin mixture for overnight. Specimens were placed in capsules that contained embedding medium and heated at $70^{\circ} \mathrm{C}$ for approximately $9 \mathrm{~h}$. Specimen sections were stained using uranyl acetate and alkaline lead citrate for $15 \mathrm{~min}$, and observed using a transmission electron microscope (TEM) Model JEM-1230 (JEOL, Tokyo, Japan). As a control, bacteria were mock incubated and prepared for embedding or thin-section electron microscopy in the same way as the peptide-treated bacteria.

\section{Statistical Analysis}

Unless otherwise noted, all experiments were carried on 3 independent occasions with at least 4 replicates and data are expressed as the mean \pm standard error. Statistical significance was determined using ANOVA with SPSS 13.0 (SPSS Inc., Chicago, IL).

\section{RESULTS}

\section{Design and Synthesis of LFP-20 Analogs}

The amphipathic nature of antimicrobial peptides plays an important role against target cells. Furthermore, several parameters, including net positive charge, $\alpha$-helicity, and overall hydrophobicity, have been shown to modulate the antibiotic activity $\alpha$-helical amphipathic antimicrobial peptides (Saberwal and Nagaraj, 1994). This is the true for LFP-20, which shows a similar pattern, with both hydrophobic and hydrophilic regions. To elucidate the relationship between hydrophobic and hydrophilic regions and to design novel peptides with more potent antimicrobial activity than LFP-20, we designed and synthesized several peptide analogs with the same cationic AA number and more hydrophobic AA of LFP-20. Tryptophan was substituted to increase hydrophobicity of the peptide. To exclude the influences of disulfide bridge formed possibly by 2 Cys of LFP-20, we also use of peptide LF2A, without disulfide potential, as another control. The AA sequences used in this study are summarized in Table 1. Synthetic peptides were purified using reverse-phaseHPLC and the correct molecular weights of the synthetic peptides were confirmed using matrix-assisted laser desorption/ionization (MALDI) mass spectrometry (Table 2). Trifluoroacetic acid is popularly used as a strong acid in peptide synthesis and used as an ion pairing agent in HPLC of peptides. This compound is also known to bind to the synthetic peptides and could affect the physiological responses or alter conformation of peptides, and thus would enhance the substitutional affects. We supplied the concentrations of trifluoroacetate in peptides' aqueous solution used in this study for better comparison (Table 2).

Porcine lactoferricin is a 30-residue amphipathic antimicrobial peptide (Table 1) with moderate antimicrobial activity but very low toxicity to human cells. Likewise, LF2A are peptides with Ala substitutions at position 2 and 17 of LFP-20. The peptides LF-2, LF-4, and LF-6 contain Ala, Ser, and Trp substitutions at 
Table 1. Amino acid sequences of synthetic antimicrobial peptides, 20-residue bovine lactoferricin (LFP-20), lactoferricin (LF) 2A, LF-2, LF-4, and LF-6

\begin{tabular}{llll}
\hline Name & AA sequence $^{1}$ & Size & Remark \\
\hline LFP-20 & KCRQWQSKIRRTNPIFCIRR $_{\text {LF2A }}$ & 20 & Native, no S-S \\
KF-2 & KARQWQSKIRRTNPIFAIRR & 20 & $\mathrm{C}^{2}, \mathrm{C}^{17} \rightarrow \mathrm{A}^{2}, \mathrm{~A}^{17}$ \\
LF-4 & KSRQWQWKIRRTWPIFAIRR & 20 & $\mathrm{C}^{2}, \mathrm{~S}^{7}, \mathrm{~N}^{13}, \mathrm{C}^{17} \rightarrow \mathrm{A}^{2}, \mathrm{~W}^{7}, \mathrm{~W}^{13}, \mathrm{~A}^{17}$ \\
LF-6 & KWRQWQSKWTWPIFSIRR & 20 & $\mathrm{C}^{2}, \mathrm{~S}^{7}, \mathrm{~N}^{13}, \mathrm{C}^{17} \rightarrow \mathrm{S}^{2}, \mathrm{~W}^{7}, \mathrm{~W}^{13}, \mathrm{~S}^{17}$ \\
\hline
\end{tabular}

${ }^{1}$ One letter AA code.

positions $2,7,13$, or 17 of LFP-20 or Trp substitutions at positions 2, 9, 15, or 17 of LFP-20 (Table 1) and were analyzed in the present study due to their activities against gram-negative and gram-positive bacteria, with the lowest toxicity against eukaryotic cells.

\section{MIC}

The MIC of LFP-20 and its analog peptides toward several gram-positive and gram-negative bacteria in MHB are shown in Table 3. The peptide LF2A showed similar antimicrobial activities toward most bacteria compared with LFP-20; LFP-20 was less active than LF-2, LF-4, and LF-6 against all microorganisms tested. The 3 analogs exerted potent and broad-spectrum activity. In comparison, LF-6 showed considerably increased activity against both the gram-negative bacteria P. aeruginosa, E. coli, S. choleraesuis, S. typhimurium, and gram-positive Staph. aureus and Staph. epidermidis. Additionally, LFP-20 and LF2A are not active against $P$. aeruginosa, whereas LF-2, LF-4, and LF-6 all exhibited 2 to 8 times lower MIC than LFP-20. Thus, the presence of an increased number of hydrophobic AA appeared to contribute to the spectrum of both activity and potency. The peptide LF-6 showed similar or higher activities compared with LF-2, particularly against $S$. choleraesuis, which exhibited an MIC 4 times lower than that of LF-2. Likewise, LF-4 showed slightly lower activity than LF-2 and LF-6 against some strains tested, but the activity of this analog was also 2 to 8 times higher than that of LFP-20.

\section{Hemolytic Activity}

The hemolytic activity of the peptides against human erythrocytes was evaluated after $18 \mathrm{~h}$ of incubation at $37^{\circ} \mathrm{C}$ (Figure 1). Both LFP-20 and LF2A exhibited the lowest hemolytic activity, at 4 to $256 \mu \mathrm{g} / \mathrm{mL}$, compared with peptides LF-2, LF-4, and LF-6 $(4-32 \mu \mathrm{g} / \mathrm{mL})$. The 3 analog peptides induced concentration-dependent hemolysis (Figure 1). The activities of the 3 analogs peptides were quantitatively similar to that of the LFP20 , which was $32 \mu \mathrm{g} / \mathrm{mL}$. The peptide LF-6 induced the highest lysis activity among the 4 peptides, with nearly $27 \%$ lysis observed at $256 \mu \mathrm{g} / \mathrm{mL}$, compared with less than 3\% hemolysis for LFP-20. Both LF-4 and LF-6 exhibited lower hemolytic activity than LF-6 (Figure 2 ), but hemolysis induced by LF-2 and LF-4 was also significantly more pronounced than that induced by LFP-20.

\section{Cell Viability Assay}

The effect of LFP-20 and its analogs on human PBMC viability was assessed using WST-1 assays. No significant variation in metabolic activity of $\mathrm{PBMC}$ was observed following incubation with LFP-20, LF2A, LF2, LF-4, or LF-6 (Figure 2).

\section{Cytotoxicity}

To assess possible host cell toxicity of LFP-20 and its analogs, LDH release experiments were performed to

Table 2. Molecular weights (MW) of the peptides determined using matrix-assisted laser desorption/ionization (MALDI) mass spectrometry and peptide mean hydrophobicities

\begin{tabular}{lccccc}
\hline & \multicolumn{2}{c}{ MW $(\mathrm{Da})$} & & & \multicolumn{2}{c}{$\begin{array}{c}\text { Concentration of } \\
\text { Name }\end{array}$} & Calculated & Observed & $\begin{array}{c}\text { Retention time } \\
(\mathrm{min})\end{array}$ & $\begin{array}{c}\text { Mean } \\
\text { trifluoroacetate in } \\
\text { peptide }(\mathrm{mg} / \mathrm{kg})\end{array}$ \\
\hline LFP-20 & $2,590.10$ & $2,590.05$ & 14.879 & -2.80 & 26.186 \\
LF2A & $2,525.90$ & $2,525.90$ & 13.951 & -2.68 & 28.243 \\
LF-2 & $2,697.27$ & $2,697.26$ & 13.543 & -1.13 & 12.193 \\
LF-4 & $2,729.26$ & $2,729.26$ & 11.952 & -1.46 & 28.265 \\
LF-6 & $2,902.40$ & $2,902.39$ & 12.007 & -1.50 & 22.788 \\
\hline
\end{tabular}

${ }^{1}$ LFP-20 = 20-residue bovine lactoferricin (LF); LF2A, LF-2, L5-4, and LF-6 are analogs to LFP-20.

${ }^{2}$ Mean values were calculated using consensus values of the hydrophobicity scale for each AA residue. 


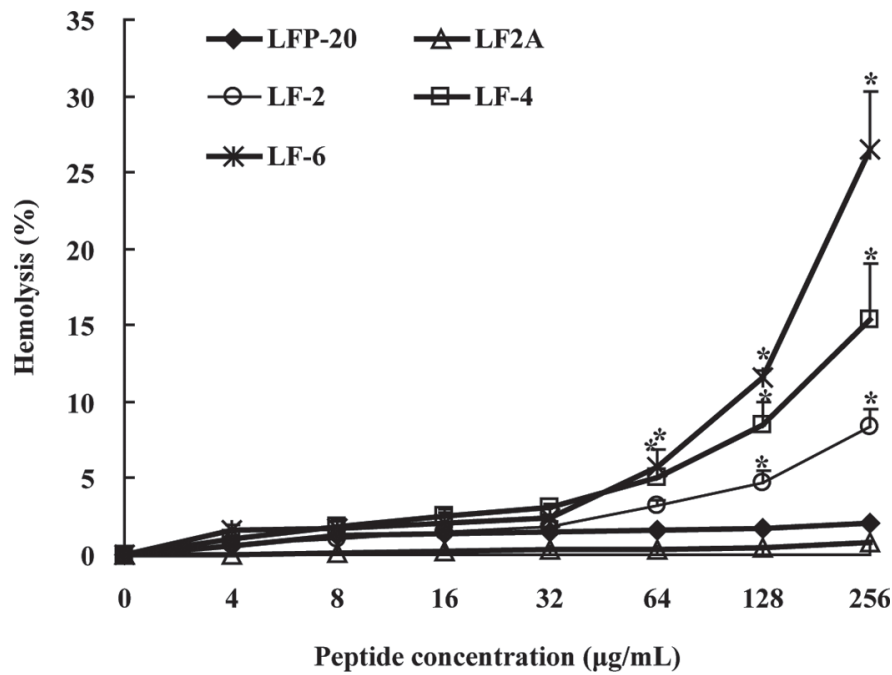

Figure 1. Concentration-response curves of the hemolytic activities of the peptides toward human erythrocytes. Lactoferricin (LF)-4 and LF-6 induced significantly more hemolysis than did 20-residue bovine lactoferricin (LFP-20) at 64 to $256 \mu \mathrm{g} / \mathrm{mL}$, whereas LF-2 induced significantly more hemolysis than did LFP-20 at 128 and $256 \mu \mathrm{g} / \mathrm{mL}$. Data were analyzed using one-way ANOVA for the factors of different peptides and peptide concentrations followed by post hoc tests, and asterisks denote significance at a $P$-value of $<0.05$ compared with cells treated with LFP-20.

measure the level of cytotoxicity exhibited by LFP-20, LF2A, LF-2, LF-4, and LF-6 toward PBMC (Figure 3). At 25 to $200 \mu \mathrm{g} / \mathrm{mL}$, dose-dependent cytotoxicity was observed in 5 peptides treated with PBMC; LFP-20, LF2A, LF-2, and LF-4 exhibited low cytotoxicity toward $\mathrm{PBMC}$ at concentrations ranging from 25 to 100 $\mu \mathrm{g} / \mathrm{mL}$. Compared with LFP-20, LF-2 and LF-4 did not cause significant cytotoxicity against PBMC in this concentration range. The peptide LF-6 exhibited the highest cytolytic effect $(P<0.05)$, from 25 to $400 \mu \mathrm{g} /$ $\mathrm{mL}$. The levels of LDH release in response to 200 and $400 \mu \mathrm{g} / \mathrm{mL}$ of LF-2 were statistically significantly dif-

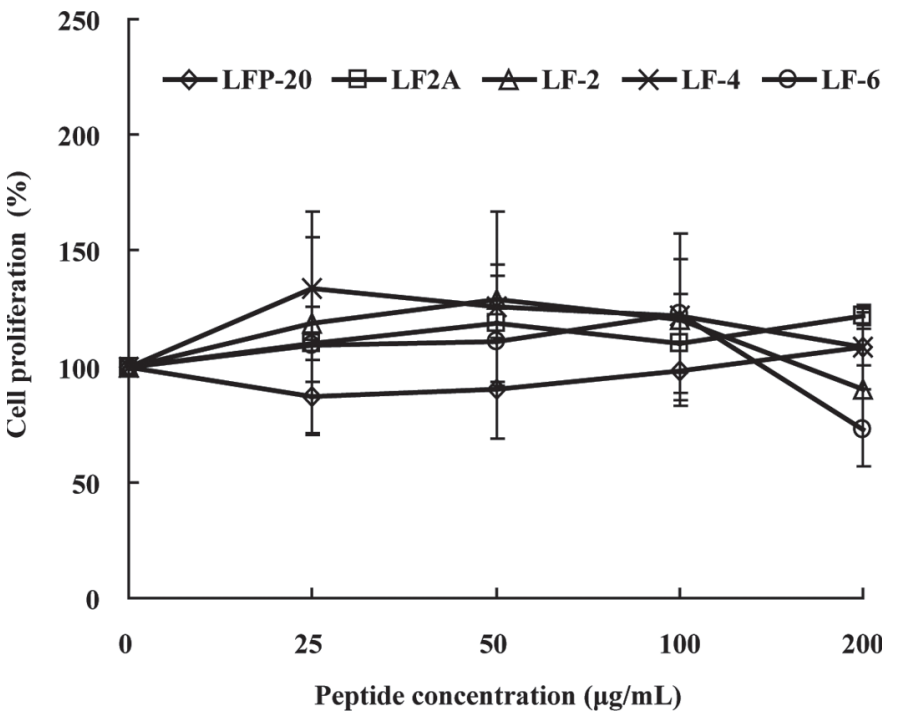

Figure 2. Effect on metabolic activity of 20-residue bovine lactoferricin (LFP-20), lactoferricin (LF) 2A, LF-2, LF-4, and LF-6 stimulated peripheral blood mononuclear cells measured based on a WST-1 (Roche Applied Science, Mannheim, Germany) assay. Metabolic activity with vehicle is set at $100 \%$. Data shown are the averages of 3 donors, measured in triplicate. Error bars shown indicate standard deviation. Statistically significant metabolic activity various versus LFP-20 values of $P<0.05$ are indicated with asterisks and were determined using ANOVA with a post hoc $t$-test.

ferent from that of cells treated with LFP-20, whereas LF-4 only exhibited higher cytotoxicity $(P<0.05)$ at $400 \mu \mathrm{g} / \mathrm{mL}$ compared with LFP-20. At the highest concentrations examined $(400 \mu \mathrm{g} / \mathrm{mL})$, we observed $60 \%$ LDH release from PBMC treated with LF-6.

\section{Cytoplasmic Membrane Depolarization Assay}

To determine whether LFP-20 and its analogs have the ability to depolarize the cytoplasmic membrane of $E$. coli, the membrane potential-sensitive dye $\mathrm{DiSC}_{3} 5$ was

Table 3. In vitro antimicrobial activities of 20-residue bovine lactoferricin (LFP-20), lactoferricin (LF) $2 \mathrm{~A}$, LF-2, LF-4, and LF-6

\begin{tabular}{|c|c|c|c|c|c|}
\hline \multirow[b]{2}{*}{ Bacteria strain } & \multicolumn{5}{|c|}{$\mathrm{MIC}(\mu \mathrm{g} / \mathrm{mL})$} \\
\hline & LFP-20 & LF2A & LF-2 & LF-4 & LF-6 \\
\hline Escherichia coli ATCC 25922 & 64 & 64 & 4 & 8 & 8 \\
\hline E. coli $\mathrm{K} 88$ & 32 & 32 & 4 & 16 & 4 \\
\hline E. coli AG1 & 128 & 64 & 8 & 16 & 4 \\
\hline E. coli JM109 & 128 & 128 & 8 & 8 & 8 \\
\hline E. coli $\mathrm{DH} 5 \alpha$ & 256 & 256 & 8 & 8 & 4 \\
\hline E. coli UB1005 & 64 & $>128$ & 8 & 8 & 4 \\
\hline Pseudomonas aeruginosa PA14 & $>256$ & $>256$ & 64 & 128 & 32 \\
\hline P. aeruginosa $\mathrm{H} 103$ & $>128$ & $>128$ & 32 & 32 & 32 \\
\hline Salmonella choleraesuis CMCC 50020 & 128 & 128 & 16 & 16 & 4 \\
\hline Salmonella typhimurium CMCC 50013 & 64 & 64 & 32 & 32 & 32 \\
\hline Staphylococcus aureus ATCC 25923 & 64 & 64 & 8 & 64 & 16 \\
\hline Staphylococcus epidermidis C621 & 128 & $>256$ & 16 & 32 & 16 \\
\hline
\end{tabular}




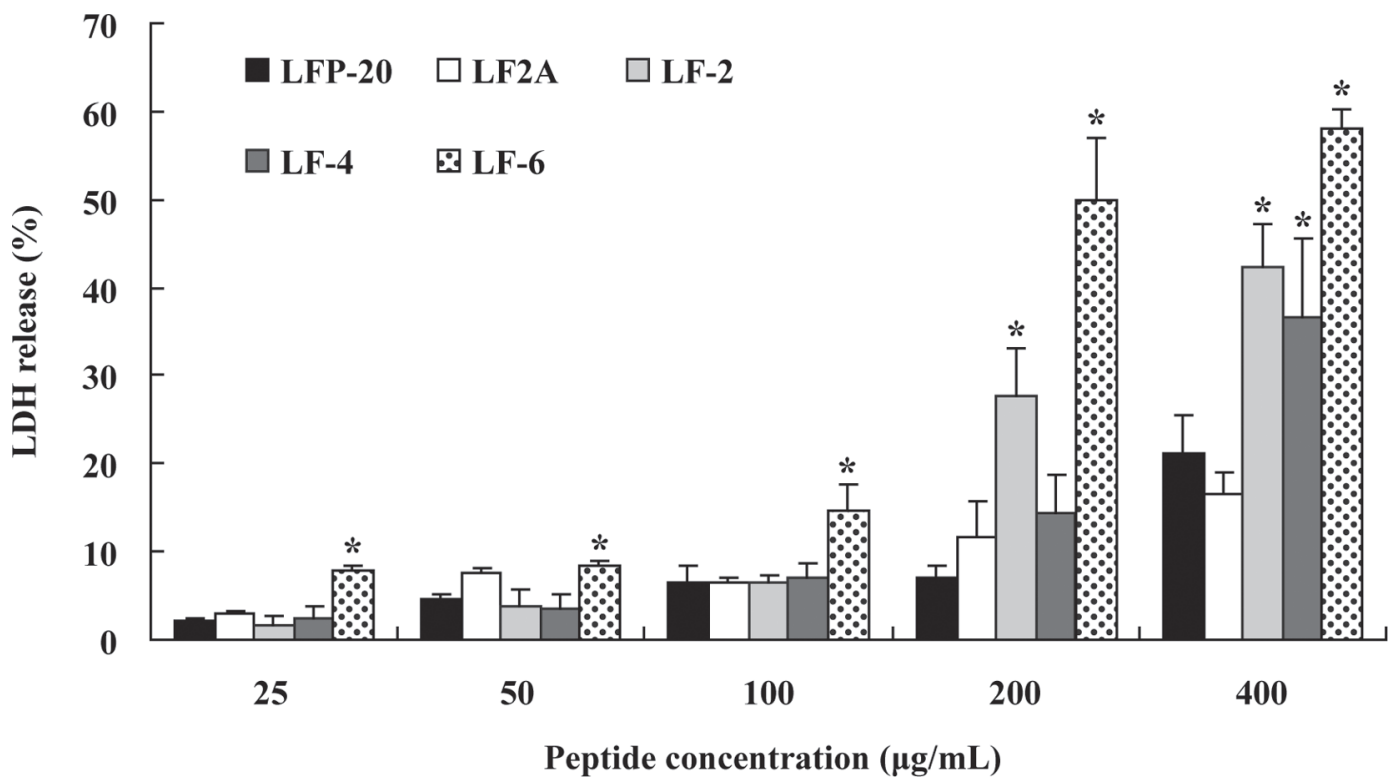

Figure 3. Human peripheral blood mononuclear cells were incubated in the presence of 20-residue bovine lactoferricin (LFP-20), lactoferricin (LF) 2A, LF-2, LF-4, and LF-6 for $18 \mathrm{~h}$. Peptide concentrations were 25 to $400 \mu \mathrm{g} / \mathrm{mL}$. Cell lysis was determined by analyzing lactate dehydrogenase $(\mathrm{LDH})$ activity released in the supernatant. Three experiments were performed with results shown as mean \pm SD. One-way ANOVA post hoc $t$-tests were performed, and asterisks denote significance at a $P$-value of $<0.05$ compared with cells treated with LFP-20.

used. This cationic dye concentrates in the cytoplasmic membrane in the presence of a membrane potential, resulting in the self-quenching of fluorescence. Upon disruption of the membrane potential, the dye dissociates into the buffer, leading to increased fluorescence (Wu et al., 1999). Depolarization was monitored over a period of $600 \mathrm{~s}$ for LFP-20 and its analogs (Figure 4); LFP-20 and its 4 analogs did not completely depolarize the cytoplasmic membrane of $E$. coli below $32 \mu \mathrm{g} /$ $\mathrm{mL}$ due to the enhanced fluorescence accompanying the increased peptide concentration. The ability of LF-2, LF-4, and LF-6 to depolarize bacterial cells was much greater than that of LFP-20 and LF2A at the lowest concentration of peptides, $4 \mu \mathrm{g} / \mathrm{mL}$, which produced an increase in fluorescence similar to the maximum utilized concentration of peptides $(32 \mu \mathrm{g} / \mathrm{mL})$. Overall, LF-2, LF-4, and LF-6 displayed 2- to 4-fold enhancement in their abilities to depolarize the bacterial cytoplasmic membrane when compared with LFP-20 or LF2A. Additionally, LFP-20 was fast-acting, achieving maximum fluorescence at $300 \mathrm{~s}$ (except at $32 \mu \mathrm{g} / \mathrm{mL}$ ). In contrast, the lag time of the other 3 analogs was much longer, leading to maximum fluorescence after $500 \mathrm{~s}$.

\section{Dansyl-Polymyxin B Displacement Assay}

The outer membrane of gram-negative bacteria, such as E. coli, is asymmetric and contains bulky glycolipids - LPS in its outer monolayer, and phospholipids in its inner monolayer. Thus, during the killing of $E$. coli cells, such peptides must interact with both membranes. Previous results suggested that differences in bacterial susceptibility to peptides were due to affinity between bacterial outer membrane components, with LPS as the most likely candidate. The initial interaction of antimicrobial peptides with the bacterial cell occurs via binding of the peptides to the anionic lipid LPS. The binding of positively charged compounds to LPS can be evaluated by examining displacement of a bound probe, dansyl-polymyxin B, which decreases fluorescence of the dansyl group (Zhang et al., 1999). The concentration of peptides resulting in 50\% maximal displacement of dansyl-polymyxin $\left(\mathrm{I}_{50}\right.$ value $)$ can be used as an indicator of relative binding affinity.

We investigated the differences in LPS affinity between LFP-20 and its analogs by monitoring displacement of previously bound dansyl-polymyxin B; results are shown in Table 4 . All 4 peptides were able to displace dansyl-polymyxin $\mathrm{B}$, which had been prebound to LPS; the affinity and avidity of the interaction varied. Both LFP-20 and LF2A displaced more dansyl-polymyxin B than nondansylated-polymyxin B, with values of 68 and $82 \%$, respectively. One-half of the LFP-20 and LF2A concentration required for maximal LPS binding was 17.3 and $48.47 \mu \mathrm{g} / \mathrm{mL}$, respectively. Interestingly, LFP-20 and LF2A were the least active of all 5 peptides in the antimicrobial assays. For LF-4 and LF-6, displacement by peptides of dansyl-polymyxin B bound to LPS showed similar affinities, which were smaller than that obtained with LFP-20. Although 
a

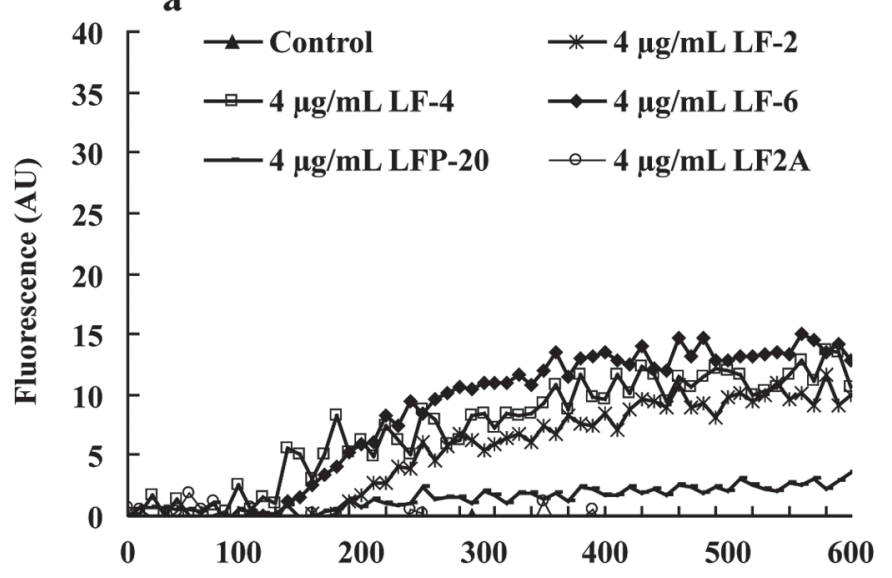

C

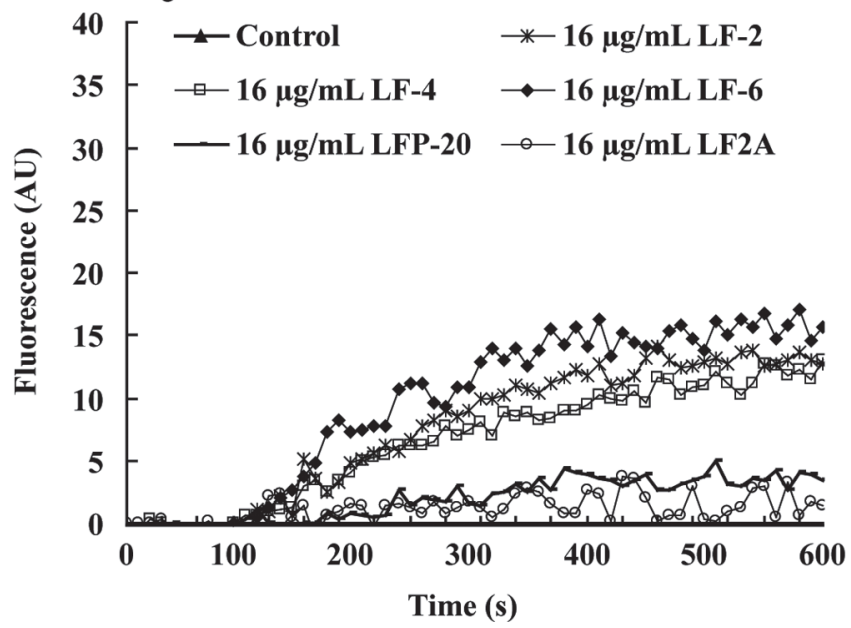

b

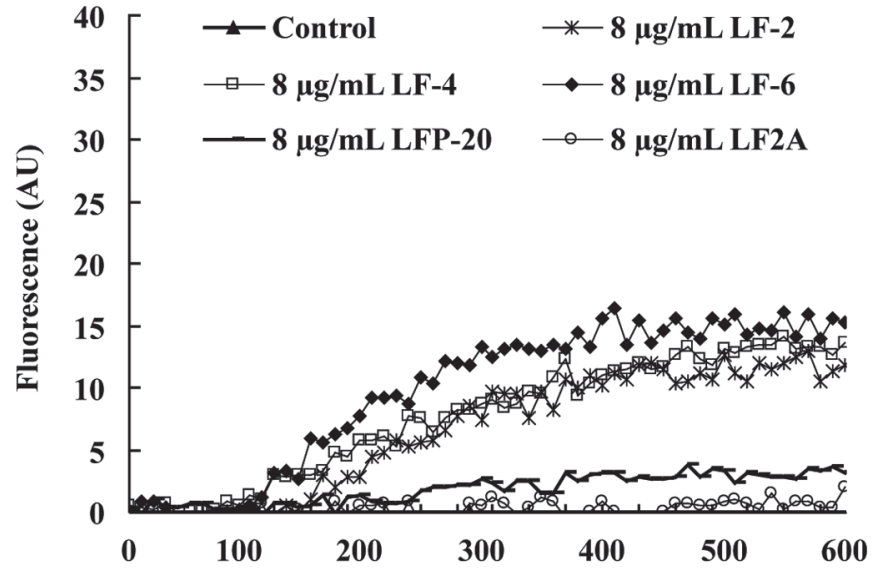

d

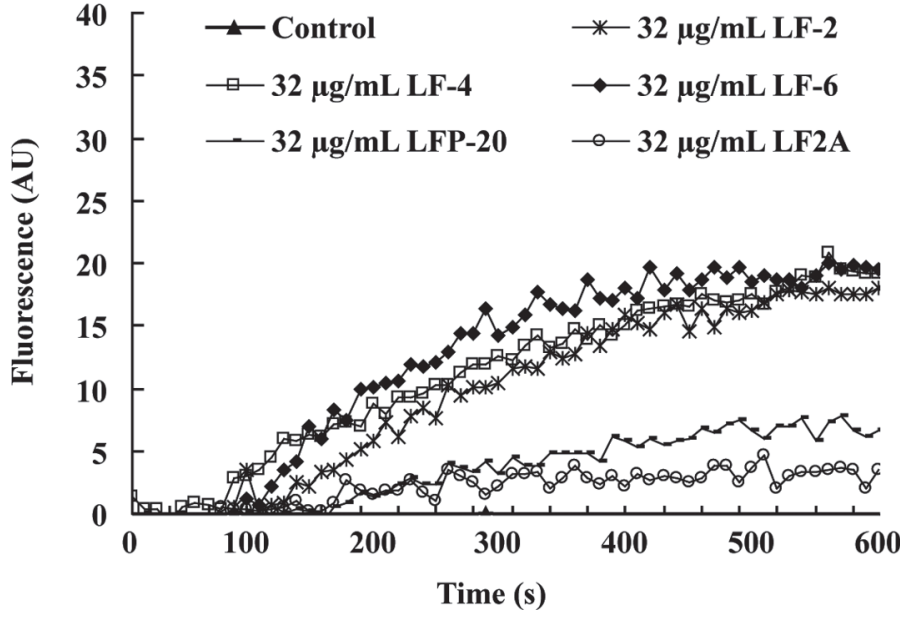

Figure 4. Cytoplasmic membrane depolarization of Escherichia coli by 20-residue bovine lactoferricin (LFP-20), lactoferricin (LF) 2A, LF2, LF-4, and LF-6 using the membrane potential-sensitive dye $\mathrm{DiSC}_{3} 5$. Fluorescence (at an excitation wavelength of $622 \mathrm{~nm}$ and an emission wavelength of $670 \mathrm{~nm}$ ) was monitored in the presence of LFP-20, LF2A, LF-2, LF-4, or LF-6. In each run, peptide was added near the 100-s time point: (a) $4 \mu \mathrm{g} / \mathrm{mL}$, (b) $8 \mu \mathrm{g} / \mathrm{mL}$, (c) $16 \mu \mathrm{g} / \mathrm{mL}$, (d) $32 \mu \mathrm{g} / \mathrm{mL}$. Data are representative of 3 independent experiments, each of which showed reproducible trends. Fluorescence is measured in arbitrary units (AU).

LF-2 showed similar antimicrobial activity to LF-4, its binding affinity compared with that of LFP-20 is differed significantly.

\section{Outer Membrane Permeabilization Activity}

In the case of gram-negative bacteria, the outer membrane plays a role as a drug barrier (Helander et al., 2001). The hydrophobic fluorophor NPN is normally prevented from entering cells because it cannot penetrate the outer membrane. When outer membranes are damaged and functionally compromised, NPN is partitioned into perturbed outer membranes, exhibiting strong fluorescence in this hydrophobic environment (Loh et al., 1984). To address the possibility that the analogs had altered outer membrane permeability, outer
Table 4. Displacement of dansyl-polymyxin bound to LPS from Escherichia coli UB1005 by 20-residue bovine lactoferricins (LFP-20), lactoferricin (LF) 2A, LF-2, LF-4, and LF-6

\begin{tabular}{lcc}
\hline & \multicolumn{2}{c}{ LPS from E. coli UB1005 } \\
\cline { 2 - 3 } Peptide & $\mathrm{I}_{\max }{ }^{1}(\%)$ & $\mathrm{I}_{50}{ }^{2}(\mu \mathrm{g} / \mathrm{mL})$ \\
\hline LFP-20 & 68 & 17.30 \\
LF2A & 82 & 48.47 \\
LF-2 & 26 & 8.70 \\
LF-4 & 56 & 7.96 \\
LF-6 & 51 & 6.91 \\
\hline
\end{tabular}

${ }^{1} \mathrm{I}_{\max }$, maximal displacement of dansyl polymyxin $\mathrm{B}$ by various peptides compared with displacement caused by nondansylated polymyxin B, which is taken as $100 \%$.

${ }^{2} \mathrm{I}_{50}$, one-half of the peptide concentration required for maximum LPS binding. 
membrane permeabilization of E. coli by LFP-20 and its analogs were evaluated using the hydrophobic NPN fluorescent probe (Figure 5). Addition of peptides (2-32 $\mu \mathrm{g} / \mathrm{mL}$ ), except for LFP-20, to E. coli suspensions in the presence of NPN caused a dose-dependent increase in fluorescence. No obvious difference was observed in the abilities of LFP-20 and the 4 analogs to permeabilize the outer membrane of $E$. coli at concentration of 2 and $4 \mu \mathrm{g} / \mathrm{mL}$. However, the 4 analogs at concentrations of 8 to $32 \mu \mathrm{g} / \mathrm{mL}$ were able to permeabilize $E$. coli outer membranes to a greater extent than LFP-20 ( $P$ $<0.05$ ). Thus, the super susceptibility of the $E$. coli to the 3 analogs, LF-2, LF-4, or LF-6, correlated with an outer membrane more easily permeabilized by the novel antimicrobial peptides. However, LF2A did not exhibit stronger antimicrobial activities against E. coli, although it has greater outer membrane permeability than LFP-20 at concentrations of 8 to $32 \mu \mathrm{g} / \mathrm{mL}$.

\section{Inner Membrane Permeabilization Activity}

The ability of LFP-20 and its analogs to permeate gram-negative bacteria inner membrane was investigated as a function of cytoplasmic $\beta$-galactosidase release using the lactose permease-deficient strain $E$. coli ML-35. When cells were treated with peptides, a slow progressive release of cytoplasmic $\beta$-galactosidase was observed, which did not reach steady state after 60 min (Figure 6). An abrupt release of cytoplasmic $\beta$-galactosidase was observed for up to $20 \mathrm{~min}$ after peptide addition. In control suspensions, no obvious release of cytoplasmic $\beta$-galactosidase was detected until
60 min. All peptides showed inner membrane permeabilization activity to $E$. coli except for LF2A. Release of cytoplasmic $\beta$-galactosidase caused by LFP-20, LF-2, LF-4 and LF-6 were dose-dependent. Peptides LF-2, LF-4, and LF-6 more strongly permeabilized the $E$. coli inner membrane than did LFP-20 at concentrations of 8,16 , and $32 \mu \mathrm{g} / \mathrm{mL}$, whereas LF- 6 caused the highest release of cytoplasmic $\beta$-galactosidase among the 4 peptides. When the concentration of peptides increased to $64 \mu \mathrm{g} / \mathrm{mL}$, comparable release of cytoplasmic $\beta$-galactosidase was detected following addition of LFP-20 and its 3 analogs, particularly up to $20 \mathrm{~min}$ after peptide addition.

\section{Calcein Leakage Assay}

To investigate the membrane disruption ability of LFP-20 and its analogs, calcein was served as a marker for membrane damage and the release of entrapped calcein from liposomes was monitored fluorometrically following exposure to antimicrobial peptides. The LUV composed of PE/POPG/CL (80: 15: 5, w/w) were employed to mimic E. coli cytoplasmic membrane or make liposomes, including 3:1 mixture of POPC and POPG, 1:1 mixture of POPC and POPG, or highly anionic POPG. Peptide LFP-20 and its 3 analogs showed similar potencies toward all tested liposome types at lower concentrations (16 and $32 \mu \mathrm{g} / \mathrm{mL}$; Figure 7 ). When added to PE/POPG/CL liposomes, LFP-20, LF-2, LF-4, and LF-6 induced less than $15 \%$ calcein release, even at peptide concentrations up to $64 \mu \mathrm{g} /$ $\mathrm{mL}$ (Figure 7a). Four peptides showed similar disrup-

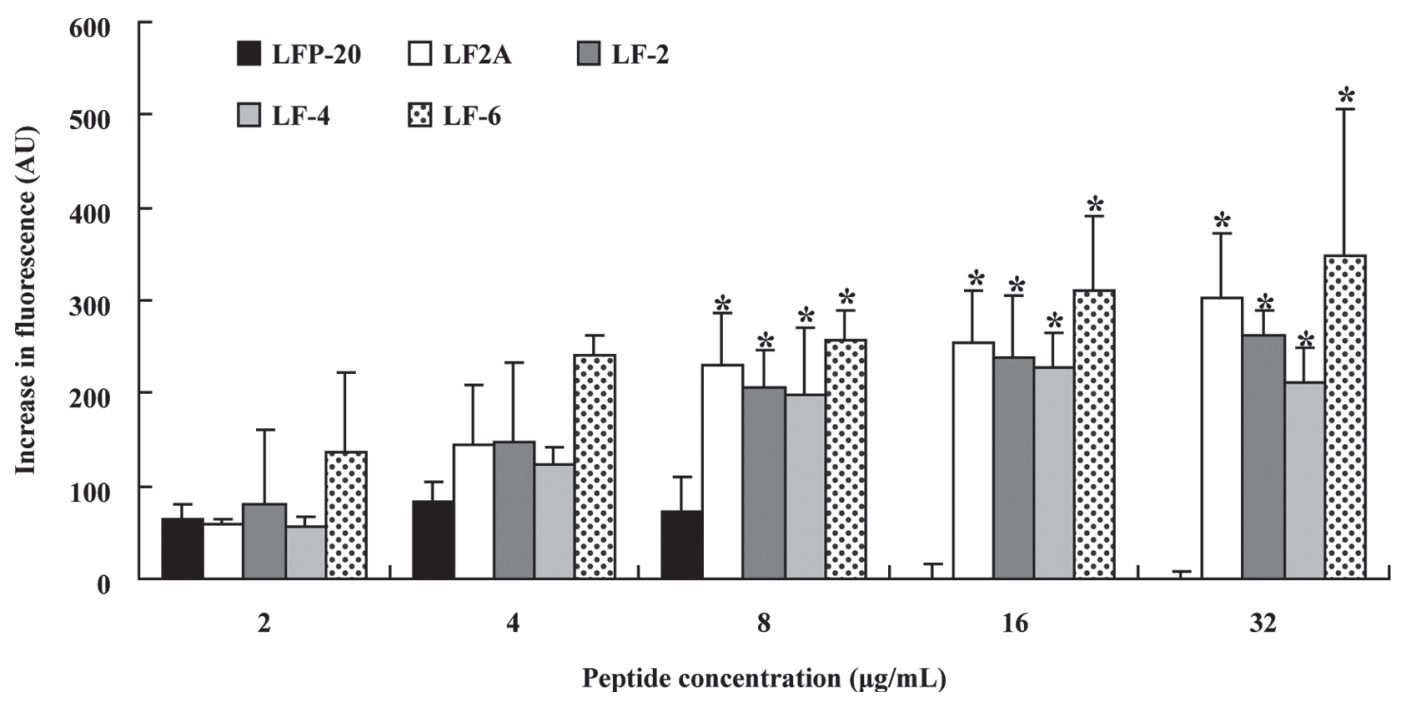

Figure 5. Uptake of N-phenyl-1-naphthylamine (NPN) by the Escherichia coli outer membrane following the addition of peptides. Cells

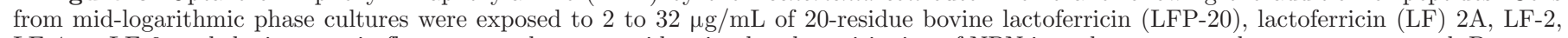

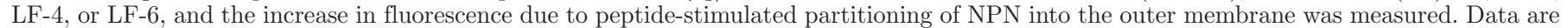

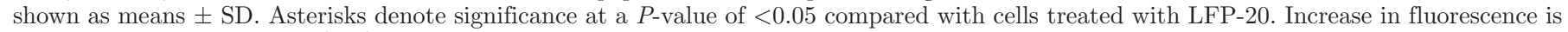
measured in arbitrary units (AU). 
$\mathbf{a}$

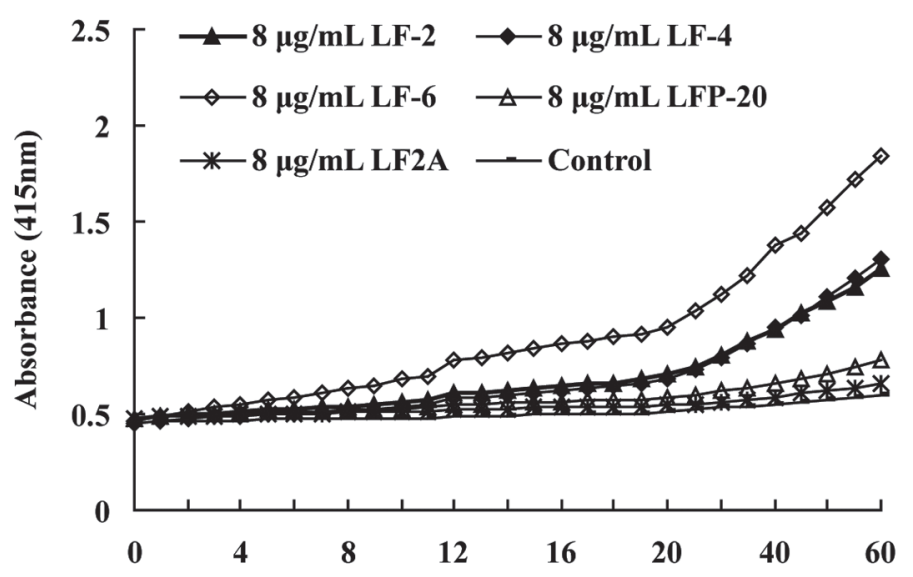

c

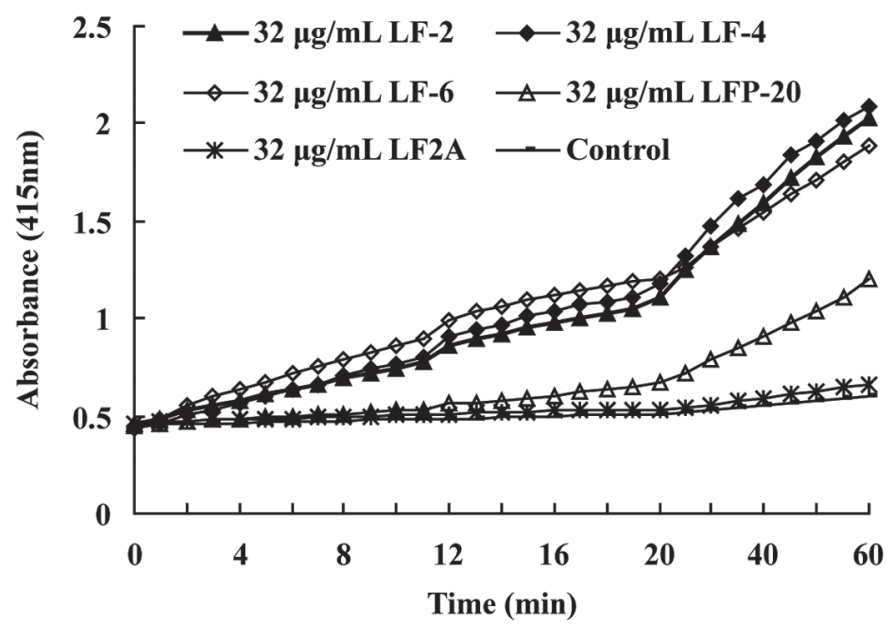

b

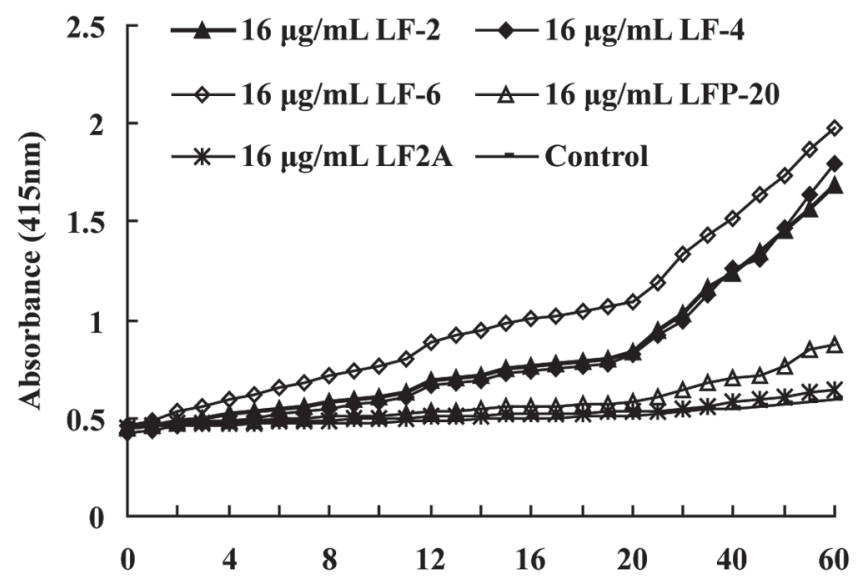

d

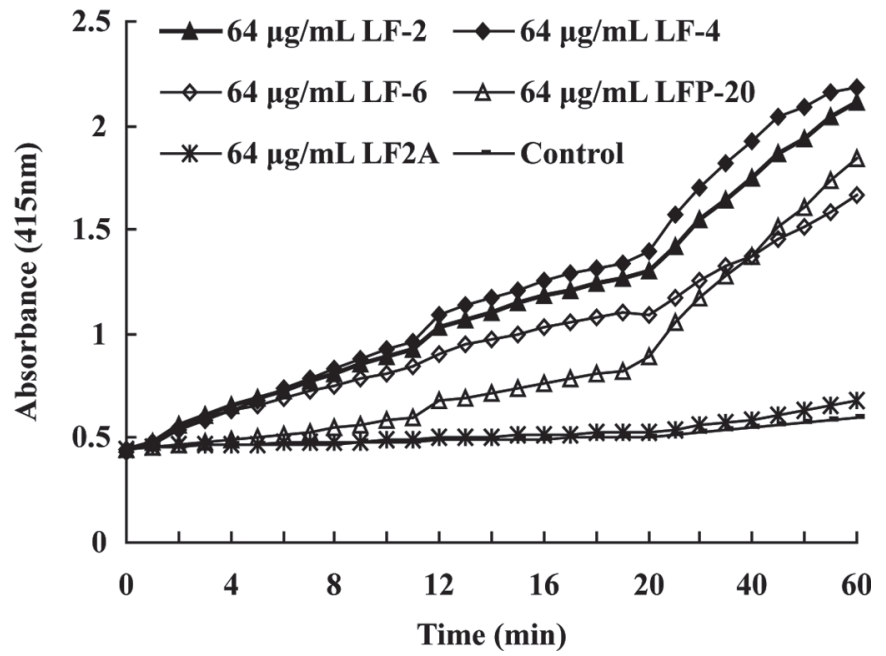

Figure 6. Release of cytoplasmic $\beta$-galactosidase activity of Escherichia coli cells treated with 20-residue bovine lactoferricin (LFP-20), lactoferricin (LF) 2A, LF-2, LF-4, or LF-6 at different concentrations: (a) $8 \mu \mathrm{g} / \mathrm{mL}$; (b) $16 \mu \mathrm{g} / \mathrm{mL}$; (c) $32 \mu \mathrm{g} / \mathrm{mL}$; (d) $64 \mu \mathrm{g} / \mathrm{mL}$.

tion activity against POPC/POPG (3:1) liposomes, but showed variable activity against POPC/POPG (1: 1) and POPG liposomes. Four peptides induced $20 \%$ or more release of calcein from POPC/POPG (3: 1) liposomes at $64 \mu \mathrm{g} / \mathrm{mL}$, which was not significantly different between LFP-20 and its analogs (Figure 7b). The peptides LF-2, LF-4, and LF-6 showed relatively strong activity against anionic POPC/POPG (1: 1) and POPG liposomes (up to $40 \%$ leakage at a concentration of $64 \mu \mathrm{g} / \mathrm{mL}$ ) compared with LFP-20 (Figure 7c, 7d), supporting the hypothesis that aggregation properties correlate with peptide hemolytic and antimicrobial activity. Peptide LFP-20 showed significantly less activity (10\% release at $64 \mu \mathrm{g} / \mathrm{mL}$ ) than the analogs, suggesting that the increase in Trp residues significantly alters selective activity against anionic membranes. The 3 analogs showed strong membrane disruption activities against negatively charged membranes, showing an increase in antimicrobial activity.

\section{Characterization of the Mode of Action Observed Using Scanning Electron Microscopy}

Scanning electron microscopy was used to visualize potential membrane damage to $E$. coli after 1 h of contact with the peptides (Figure 8). The cell surfaces of bacteria in contact with the control buffer were smooth in appearance (Figure 8a). In contrast, contact with the peptides dramatically affected membrane surface morphology. Surfaces of bacteria in contact with the LFP-20 (Figure 8b), LF2A (Figure 8c), LF-2 (Figure 8d), LF-4 (Figure 8e), and LF-6 (Figure 8f) at MIC were characterized by a distribution of small protuberant structures, or blebs. Scanning electron microscope 
a)

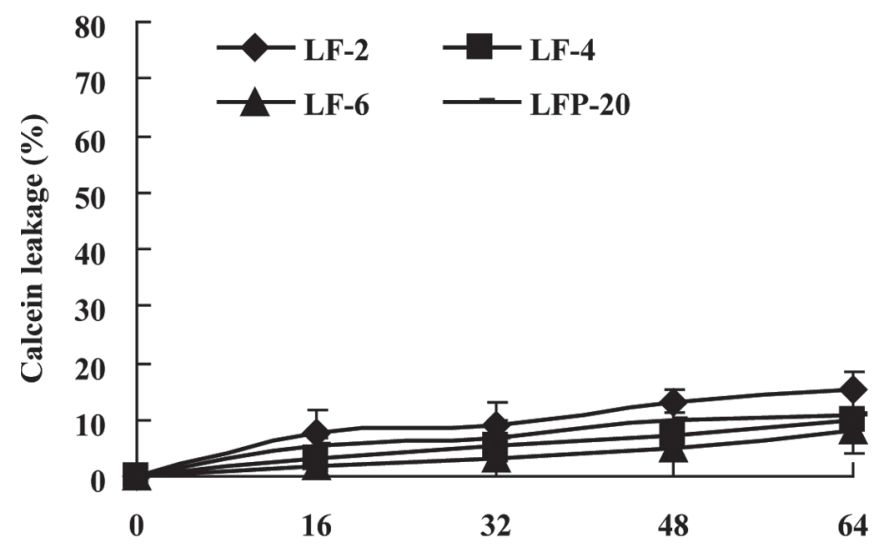

c)

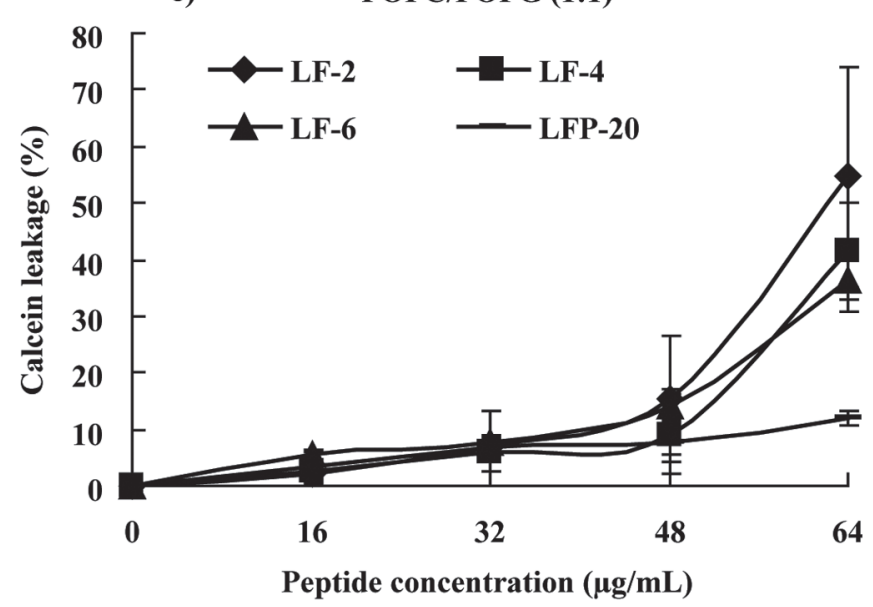

b)

POPC/POPG (3:1)

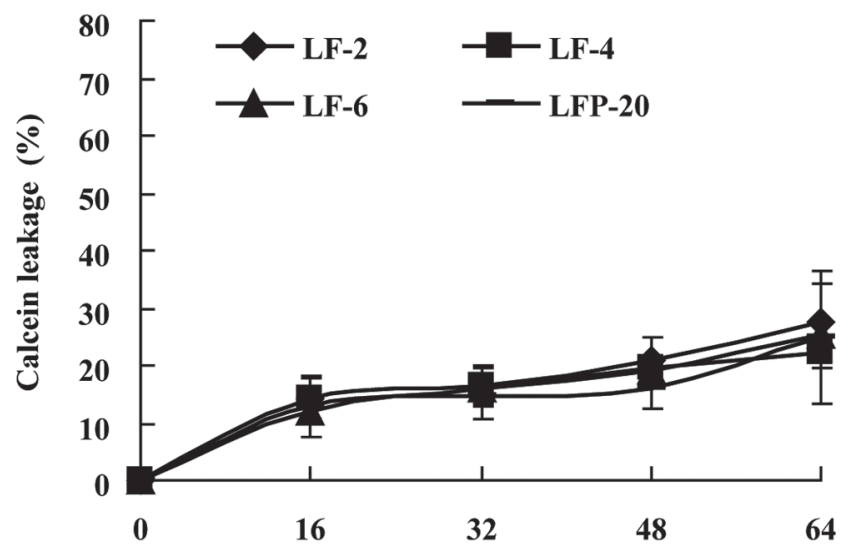

d)

POPG

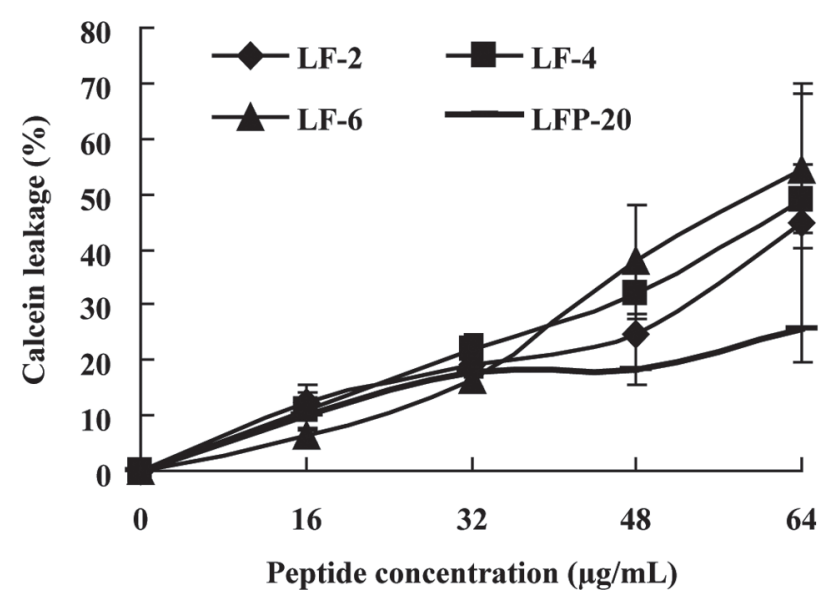

Figure 7. Dose-dependent leakage of calcein from liposomes. Calcein release from 1-palmitoyl-2-oleoyl-sn-glycero-3-phosphoethanolamine (PE)/1-palmyitoyl-2-oleoyl-sn-glycero-3-phospho-rac(1 glycerol) (POPG)/cardiolipin (85:15:5; CL; a), 1-palmyitoyl-2-oleoyl-sn-glycero-3-phosphocholine (POPC)/POPG (3:1; b), POPC/POPG (1:1; c), and POPG (d) liposomes was defined as the percent release after 10 min at a lipid concentration of $35 \mathrm{mM}$. Each data point is the mean of 3 independent experiments. LPF-20 = 20-residue bovine lactoferricin; LF $=$ lactoferricin.

microphotographs in Figure 8 confirmed membrane damage, as peptide exposure caused considerable blebbing on E. coli surface.

\section{Antimicrobial Activity Observed Using Transmission Electron Microscopy}

The effect of treating $E$. coli with the 5 peptides is shown in transmission electron micrographs (Drin and Temsamani, 2002; Figure 9). These micrographs showed that the 5 peptides had a dramatic effect on bacterial cell surface morphology, whereas untreated bacteria appeared to be smooth (Figure 9 a). After 1 $\mathrm{h}$ of incubation with the MIC of LFP-20 (Figure 9b), LF2A (Figure 9c), LF-2 (Figure 9d), LF-4 (Figure 9e), and LF-6 (Figure 9f), outer surface thickening and blebs were discernible. Blebs of the cytoplasmic membrane were more easily seen when the surface of peptide-treated bacteria were visualized using scanning electron microscopy. The LFP-20-treated bacteria cytoplasmic membrane showed invagination, and the space between the cell wall and plasma membrane appeared to be swollen. Following treatment of E. coli cells with LF-2, LF-4, and LF-6, membrane discontinuity, leakage of all cytoplasmic contents, and the appearance of vacuoles in the cytoplasm were evident. These similar results indicated that all peptides exert their activities by similar mechanisms, which leads to the severe damage, numerous blebs, and leakage of cytoplasmic contents, a well-known phenomenon observed when bacterial cells are exposed to cationic peptides.

\section{DISCUSSION}

Lactoferrins are glycoproteins found in many external secretions of mammals (Cohen et al., 1987), which 

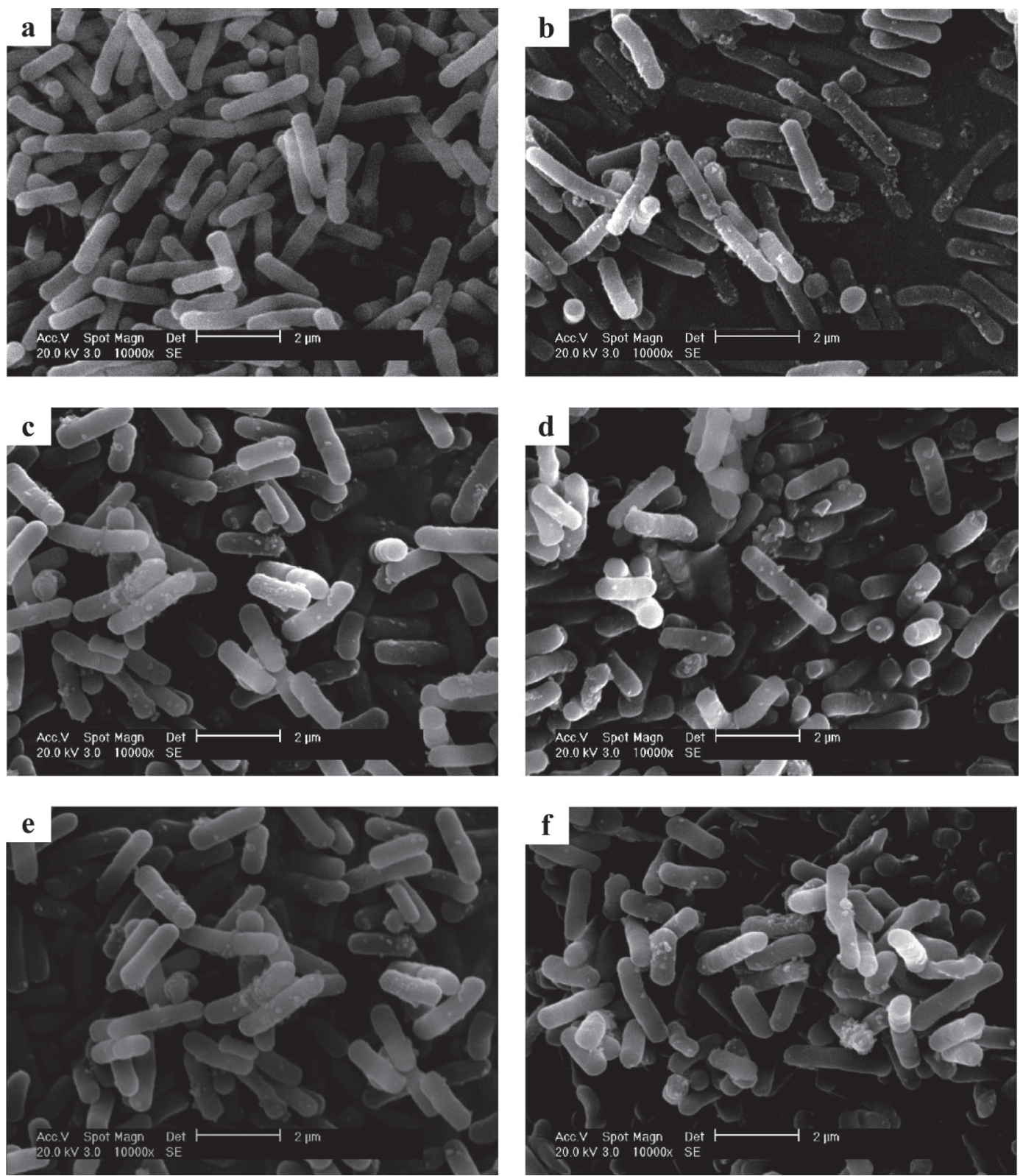

Figure 8. Morphological changes induced by 20-residue bovine lactoferricin (LFP-20), lactoferricin (LF) 2A, LF-2, LF-4, and LF-6 were visualized using scanning electron microscopy. Scanning electron micrographs of Escherichia coli cells that were in contact with (a) vehicle $(10,000 \times)$, (b) LFP-20, (c) LF2A, (d) LF-2, (e) LF-4, and (f) LF-6. Bacteria were incubated in contact with peptides for 30 min at $37^{\circ} \mathrm{C}$ before fixation and preparation for scanning electron microscopy.

are known to possess antimicrobial activity. Previous studies reported that cationic peptides, isolated after degradation of bovine and human lactoferrin by gastric pepsin, display higher antimicrobial activity than the native protein. These peptide fragments were named bovine LF (LFB) and human LF (LFH) and possess antimicrobial activities against a wide variety of microorganisms, including gram-positive and gram-negative bacteria as well as fungi (Tomita et al., 1991; Bellamy et al., 1992; Bellamy et al., 1993). The bactericidal effects of lactoferrin and LF have been the subjects of intensive study for at least 2 decades, but porcine lactoferricin has been less well-examined. In a previous study, Chen et al. (2006a) identified the potential porcine LF region using sequence-homologous clustering and studied the antimicrobial activity of short derivatives of porcine, bovine, and human LF. Of these peptide sequences, LFP-20 was 2 AA shorter within its cyclic domain than LF obtained from 8 other species, which had a moderate antimicrobial effects on E. coli, Staph. 

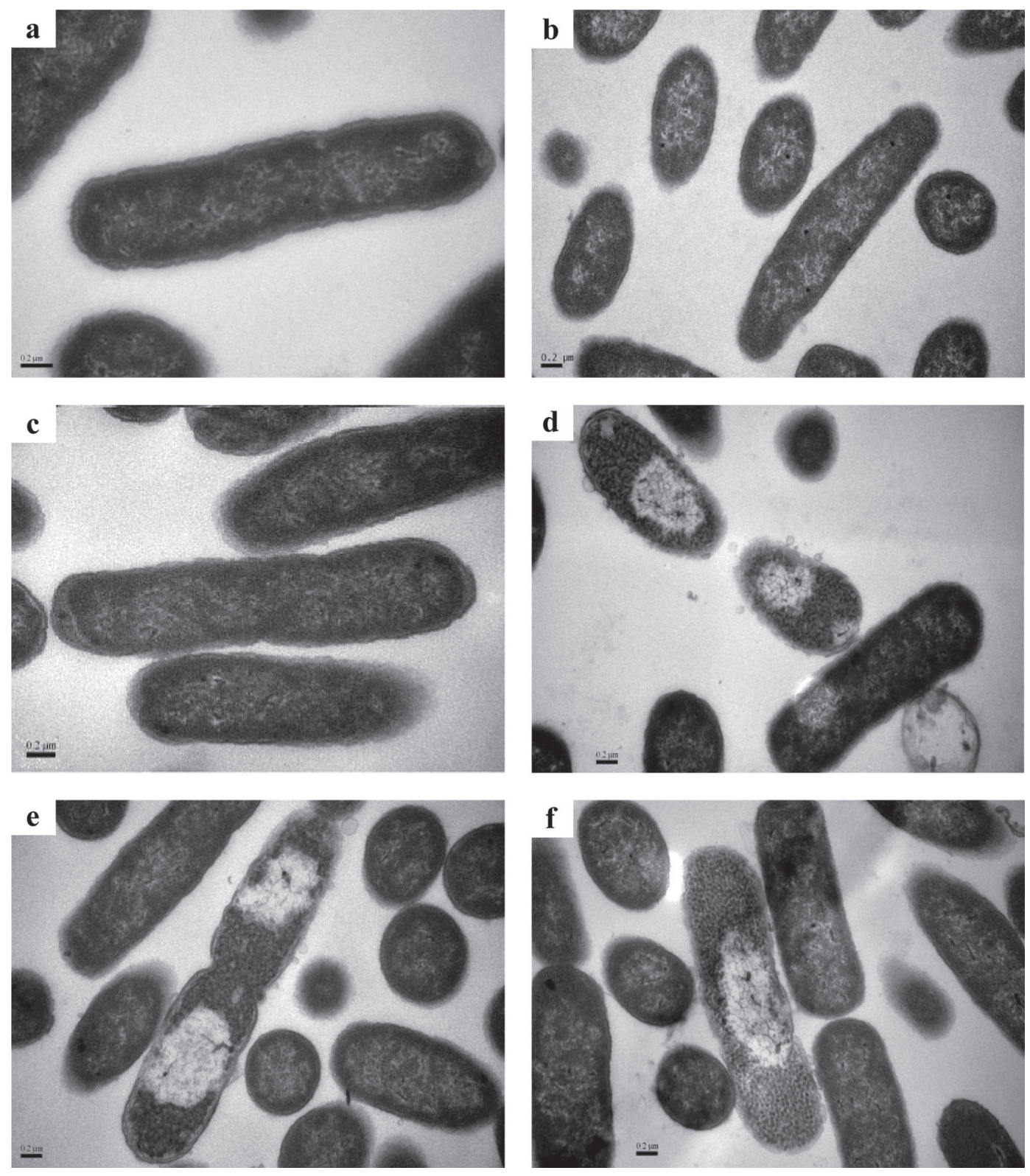

Figure 9. Transmission electron micrographs (TEM) of Escherichia coli treated with peptides: (a) E. coli cell without peptide, (b) 20-residue bovine lactoferricin (LFP-20), (c) lactoferricin (LF) 2A, (d) LF-2, (e) LF-4, and (f) LF-6. Bacteria were incubated in contact with peptides for $30 \mathrm{~min}$ at $37^{\circ} \mathrm{C}$ before fixation and preparation for TEM.

aureus, and Candida albicans (Chen et al., 2006a). In our previous study, we found little activity was lost by the reduction of the disulfide bridge for $\mathrm{LFB}$, but the hemolytic activity was slightly raised (Liu et al., 2011). This result was contradicted by Jenssen et al. (2004), who suggested that the deficiency of this loop structure could loosen or weaken the antibiotic activity. Thus, the role of the disulfide bonds is still controversial. From a chemical synthesis view of peptides, the formation of specific patterns of disulfide bonds and the subsequent purification and identification are labor intensive and resource-consuming. Therefore, this study focused on investigating homologous peptides prepared from the sequences of linear LFP-20, and their antimicrobial specificity and possible membrane mechanisms of action.

We reported that LFP-20 exhibits antibacterial activities against E. coli, S. choleraesuis, S. typhimurium, Staph. aureus, and Staph. epidermidis, but has little activity against $P$. aeruginosa. Furthermore, we investigated the effects of Trp on antimicrobial specificity and plausible mechanisms of antimicrobial action for 
LFP-20 and its analogs. Linear analogs of LFP-20 with Cys substituted with Ala (LF2A) exhibit a similar antimicrobial activity to LFP-20, indicating that the 2 Cys of LFP-20 are not essential for its antimicrobial activity. Linear analogs (LF-2, LF-4, and LF-6), with Cys substituted by Trp, exhibited a 4- to 64-fold improved antimicrobial activity as compared with LFP-20, indicating that increased Trp might be contribute to the improved antimicrobial activity. In previous studies, it also has been reported that shorter derivatives of LFB without the disulfide bond also exhibit antimicrobial activity (Kang et al., 1996). Otherwise, Trp residue is thought to function as an anchor in membrane proteins (Schiffer et al., 1992), and has been suggested to act as a key factor that pulls antimicrobial peptides across phospholipid membranes (Wimley and White, 2000).

Because antibacterial activity and cytotoxicity against host cells are intricately linked, we also investigated the toxic effects of LFP-20 and its analogs on host cells. Interestingly, the highly antimicrobial LF-2 and LF-4 peptides exhibited very limited hemolysis toward human erythrocytes below $128 \mu \mathrm{g} / \mathrm{mL}$ and only low cytotoxicity toward PBMC. This can be explained by the lower mean hydrophobicity and amphipathicity (Table 1), a feature known to affect cytotoxicity more than antibacterial activity (Zelezetsky et al., 2005; Zelezetsky and Tossi, 2006).

Understanding the modes of action of LFP-20 and its analogs is of interest because AMP are potential therapeutic agents. Due to emerging multidrug-resistant strains of bacteria, AMP have been considered as possible alternatives to conventional antibiotics. Several antimicrobial peptides have been extensively studied to elucidate their modes of antimicrobial action. The antimicrobial effect of most AMP is thought to occur on bacterial cell membranes, either by pore formation, membrane thinning, or bilayer destabilization. This results in lysis of bacterial cells due to increased permeability (Matsuzaki, 1998; Heller et al., 2000; Wang et al., 2009); however, some antimicrobial peptides have also been reported to have intracellular targets (Hale and Hancock, 2007). The peptide LFP-20 was not effective in depolarizing the cytoplasmic membranes of $E$. coli, whereas its analogs depolarized the membrane potential against intact $E$. coli nearly 3 - to 4 -fold more than LFP-20 at concentrations of 4 and $8 \mu \mathrm{g} / \mathrm{mL}$ (MIC for E. coli of LF-2, LF-4, and LF-6), suggesting the analogs kill microorganisms by dissipating membrane potential by forming pore channels on bacterial cell membranes.

The cationic antimicrobial peptide interacts with the highly negatively charged O-specific oligosaccharide units of the outer membrane containing anionic LPS. Destabilization of the outer membrane is necessary to gain access to the inner membrane. Next, AMP insert and translocate across the outer bilayer via a self-promoted uptake pathway to reach the inner membrane (Mangoni et al., 2004). The outer membrane of gram-negative bacteria with LPS and proteins is held together by electrostatic interactions involving divalent cations that are required to stabilize outer membrane structure and function. Polycationic molecules can bind negatively charged O-specific oligosaccharide units of the $E$. coli LPS, thus disrupting the integrity of the outer membrane and resulting in a loss of barrier function or blocking the nutrient flow with concomitant bacterial death due to nutrient depletion (Je and Kim, 2006). Both LFB and LFH reportedly have the ability to bind and release LPS from the outer membrane of gram-negative bacteria (Yamauchi et al., 1993) and LFB can bind teichoic acid originating from gram-positive bacteria (Vorland et al., 1999). We found LF-2, LF-4, and LF-6 have a higher potential to alter membrane permeability by dispersing membrane components such as LPS in gram-negative bacteria, leading to death of the organisms (Table 4). Peptides LF-2, LF-4, and LF-6 caused increased bacterial membrane permeability, as determined based on the internalization of the fluorescent probe NPN and cytoplasmic $\beta$-galactosidase activity (Figure 5 and Figure 6). Similar results were reported for $E$. coli treated with chitosan, magainin, and tachyplesin I (Liu et al., 2004). Helander et al. (2001) also reported that relatively high concentrations of chitosan were required to cause significantly increased NPN uptake.

The higher potency of the peptides with respect to LFP-20 analogs suggests that they may have a high inner membrane-permeabilizing capacity. This was examined by measuring the kinetics of ONPG hydrolysis in the E. coli ML-35 strain treated with increasing concentrations of peptide and by following unmasking of cytoplasmic hydrolases. Both peptides rapidly permeabilize inner membranes in a dose-dependent manner, starting at low concentrations (Figure 6). Peptide LFP20 shows considerably slower permeabilization kinetics, whereas the 3 analogs exhibited a more rapid release of cytoplasmic $\beta$-galactosidase. These observations point to a relevant role for Trp in the membrane permeabilization mechanism, particularly for the interaction with the inner LPS layer. The inner membrane of gramnegative bacteria is composed of anionic lipids, such as phosphatidyl glycerol and cardiolipin, which may favor cationic molecule association. Therefore, AMP bind the anionic inner membrane through electrostatic interactions.

We also assessed the ability of LFP-20 and its analogs to induce release of entrapped calcein from liposomes made up of different lipids (Figure 7). Whereas 
the 3 analogs exhibited more potential than LFP-20 to depolarize the cytoplasmic membrane of E. coli, they showed almost no obvious differences compared with LFP-20 in the leakage of calcein from the lipid vesicle mimics PE/POPG/CL (80:15:5) and POPC/POPG (3:1). However, at high concentrations, the 3 analogs caused significant dye leakage from negatively charged vesicles POPC/POPG (1:1) or POPG. In contrast, LFP-20 only caused weaker dye leakage from negatively charged vesicles, such as POPG. This leakage potency of LFP-20 and its analogs for the POPC/POPG (1:1) or POPG vesicles was consistent with hemolytic activity. Leakage potency of the peptides was correlated with their biological activities, suggesting that the biological action of the peptides may be carried out through the lipid membrane. Additionally, these results led to the hypothesis that the higher hydrophobicity of LF-2, LF-4, and LF-6 compared with LFP-20 contributes to higher antimicrobial activity and hemolytic activity of the 3 analogs. These results suggest a positive correlation between the disruption of anionic liposomes and their biological activity. Further studies are underway to understand the mechanism underlying microbial killing by these Trp-rich peptides.

Electron microscopy revealed an effect on the bacterial membrane, demonstrated by the appearance of morphological changes. In this study, formation and coalescence of multiple vesicles and blebs derived from the membrane were observed using scanning electron microscopy and transfer electron microscopy, indicating thinning, fragmentation, and disruption of the membrane (Figure 8 and Figure 9). These types of damage are typically found in bacteria with programmed cell death Type II. The 3 analogs behaved similarly, but demonstrated more obvious damage to the cytoplasmic membrane when compared with LFP-20.

A variety of alternative mechanisms of action have been proposed for the effect of AMP on bacteria (Hale and Hancock, 2007). We propose that multiple possible anionic targets exist for LFP-20 and its analogs in their action against bacteria, including the cytoplasmic membrane, cell wall, DNA, RNA, and various enzymes. These targets are also differentially accessed depending on the bacterial type. Although the exact mechanism of action of these peptides on gram-positive bacteria has not been determined, LFP-20 and its analogs kill $E$. coli via formation of small ion channels that permit transit of ions or protons, as well as molecules as large as calcein, based on the results of this study. Further insight into the mechanism of action on other bacterium will aid in the application of LFP-20 and its analogs as future therapeutics.

\section{CONCLUSIONS}

In this study, we designed and synthesized several Trp-rich analogs with amphipathic structures based on LFP-20. A comparison of the biological properties and activity of the analogs and template showed that peptide analogs exhibit strong activity against several bacterial strains to a greater extent than LFP-20 and maintained a balance between antimicrobial activity and cytotoxicity. The amphipathic nature of these peptides enables selective interaction with and disruption of negatively charged microbial membranes, resulting in a broad spectrum of antimicrobial activity with low cytotoxicity. Additionally, we demonstrated that LFP-20 induces little or no membrane depolarization of bacterial cells, dye leakage from bacterial membranemimicking lipid vesicles, or effective penetration of bacterial cell membranes. In contrast, the 3 analogs showed a potent ability to cause depolarization of the cytoplasmic membrane potential of intact $E$. coli cells, resulting in dye leakage from negatively charged vesicles. Our results suggest that analogs exhibit lethality due to their ability to form small channels that allow the transit of ions or protons and molecules as large as calcein at higher concentrations as well as by disrupting membranes. Further studies examining the clinical efficacies and mechanisms of action of LFP-20 will increase the potential of this natural AMP for use in the development of pharmaceutical compounds to overcome bacterial resistance.

\section{ACKNOWLEDGMENTS}

We gratefully acknowledge financial support received from the National High Technology Research and Development Program of China (Hangzhou, China; Grant No. 2007AA100602), National Science Fund for Distinguished Young Scholars of China (Hangzhou, China; Grant No.31025027), China Postdoctoral Science Foundation (Hangzhou, China; Grant No. 2011M500104), and Foundation for the Author of National Excellent Doctoral Dissertation of China (Hangzhou, China; FANEDD, Grant No. 2007B6). We thank R. E. W. Hancock (Centre for Microbial Diseases and Immunity Research, The University of British Columbia, Vancouver, Canada) for generously donating and guiding the assay, as well as J. Hale and M. Elliott (both from the Centre for Microbial Diseases and Immunity Research, The University of British Columbia) for their excellent technical assistance. The authors acknowledge Blair E. Aldridge (Purdue University, West Lafayette, IN) for valuable suggestions and linguistic assistance. 


\section{REFERENCES}

Bellamy, W., M. Takase, H. Wakabayashi, K. Kawase, and M. Tomita. 1992. Antibacterial spectrum of lactoferricin B, a potent bactericidal peptide derived from the N-terminal region of bovine lactoferrin. J. Appl. Bacteriol. 73:472-479.

Bellamy, W., H. Wakabayashi, M. Takase, K. Kawase, S. Shimamura, and M. Tomita. 1993. Killing of Candida albicans by lactoferricin $\mathrm{B}$, a potent antimicrobial peptide derived from the N-terminal region of bovine lactoferrin. Med. Microbiol. Immunol. (Berl.) 182:97-105.

Chen, H. L., C. C. Yen, C. Y. Lu, C. H. Yu, and C. M. Chen. 2006a. Synthetic porcine lactoferricin with a 20-residue peptide exhibits antimicrobial activity against Escherichia coli, Staphylococcus aureus, and Candida albicans. J. Agric. Food Chem. 54:3277-3282.

Chen, Y., C. T. Mant, S. W. Farmer, R. E. W. Hancock, M. L. Vasil, and R. S. Hodges. 2005. Rational design of $\alpha$-helical antimicrobial peptides with enhanced activities and specificity/therapeutic index. J. Biol. Chem. 280:12316-12329.

Chen, Y., A. I. Vasil, L. Rehaume, C. T. Mant, J. L. Burns, M. L. Vasil, R. E. W. Hancock, and R. S. Hodges. 2006b. Comparison of biophysical and biologic properties of alpha-helical enantiomeric antimicrobial peptides. Chem. Biol. Drug Des. 67:162-173.

Cohen, M. S., B. E. Britigan, M. French, and K. Bean. 1987. Preliminary observations on lactoferrin secretion in human vaginal mucus: Variation during the menstrual cycle, evidence of hormonal regulation, and implications for infection with Neisseria gonorrhoeae. Am. J. Obstet. Gynecol. 157:1122-1125.

Drin, G., and J. Temsamani. 2002. Translocation of protegrin I through phospholipid membranes: Role of peptide folding. Biochim. Biophys. Acta 1559:160-170.

Fan, Z., L. Cao, Y. He, J. Hu, Z. Di, Y. Wu, W. Li, and Z. Cao. 2011. Ctriporin, a new anti-methicillin-resistant Staphylococcus aureus peptide from the venom of the scorpion Chaerilus tricostatus. Antimicrob. Agents Chemother. 55:5220-5229.

Gordon, Y. J., E. G. Romanowski, and A. M. McDermott. 2005. A review of antimicrobial peptides and their therapeutic potential as anti-infective drugs. Curr. Eye Res. 30:505-515.

Hale, J. D., and R. E. Hancock. 2007. Alternative mechanisms of action of cationic antimicrobial peptides on bacteria. Expert Rev. Anti Infect. Ther. 5:951-959.

Hancock, R. E. W., and H. G. Sahl. 2006. Antimicrobial and hostdefense peptides as new anti-infective therapeutic strategies. Nat. Biotechnol. 24:1551-1557.

Helander, I. M., E. L. Nurmiaho-Lassila, R. Ahvenainen, J. Rhoades, and S. Roller. 2001. Chitosan disrupts the barrier properties of the outer membrane of gram-negative bacteria. Int. J. Food Microbiol. 71:235-244.

Heller, W. T., A. J. Waring, R. I. Lehrer, T. A. Harroun, T. M. Weiss, L. Yang, and H. W. Huang. 2000. Membrane thinning effect of the beta-sheet antimicrobial protegrin. Biochemistry 39:139-145.

Je, J. Y., and S. K. Kim. 2006. Antimicrobial action of novel chitin derivative. Biochim. Biophys. Acta 1760:104-109.

Jenssen, H., J. H. Andersen, L. Uhlin-Hansen, T. J. Gutteberg, and O. Rekdal. 2004. Anti-HSV activity of lactoferricin analogues is only partly related to their affinity for heparan sulfate. Antiviral Res. 61:101-109.

Kang, J. H., M. K. Lee, K. L. Kim, and K. S. Hahm. 1996. Structurebiological activity relationships of 11-residue highly basic peptide segment of bovine lactoferrin. Int. J. Pept. Protein Res. 48:357363.

Liu, H., Y. Du, X. Wang, and L. Sun. 2004. Chitosan kills bacteria through cell membrane damage. Int. J. Food Microbiol. 95:147155 .

Liu, Y., F. Han, Y. Xie, and Y. Wang. 2011. Comparative antimicrobial activity and mechanism of action of bovine lactoferricin-derived synthetic peptides. Biometals 24:1069-1078.

Loh, B., C. Grant, and R. E. W. Hancock. 1984. Use of the fluorescentprobe $1-N$-phenylnaphthylamine to study the interactions of aminoglycoside antibiotics with the outer membrane of Pseudomonas aeruginosa. Antimicrob. Agents Chemother. 26:546-551.
Mangoni, M. L., N. Papo, D. Barra, M. Simmaco, A. Bozzi, A. Di Giulio, and A. C. Rinaldi. 2004. Effects of the antimicrobial peptide temporin L on cell morphology, membrane permeability and viability of Escherichia coli. Biochem. J. 380:859-865.

Matsuzaki, K. 1998. Magainins as paradigm for the mode of action of pore forming polypeptides. Biochim. Biophys. Acta 1376:391-400.

Moore, R. A., N. C. Bates, and R. E. Hancock. 1986. Interaction of polycationic antibiotics with Pseudomonas aeruginosa lipopolysaccharide and lipid A studied by using dansyl-polymyxin. Antimicrob. Agents Chemother. 29:496-500.

Oren, Z., J. Hong, and Y. Shai. 1997. A repertoire of novel antibacterial diastereomeric peptides with selective cytolytic activity. J. Biol. Chem. 272:14643-14649.

Rathinakumar, R., W. F. Walkenhorst, and W. C. Wimley. 2009. Broad-spectrum antimicrobial peptides by rational combinatorial design and high-throughput screening: The importance of interfacial activity. J. Am. Chem. Soc. 131:7609-7617.

Saberwal, G., and R. Nagaraj. 1994. Cell-lytic and antibacterial peptides that act by perturbing the barrier function of membranes - Facets of their conformational features, structure-function correlations and membrane-perturbing abilities. Biochem. Biophys. Acta 1197:109-131.

Sang, Y., and F. Blecha. 2008. Antimicrobial peptides and bacteriocins: Alternatives to traditional antibiotics. Anim. Health Res. Rev. 9:227-235.

Schiffer, M., C. H. Chang, and F. J. Stevens. 1992. The functions of tryptophan residues in membrane proteins. Protein Eng. 5:213214

Tomita, M., W. Bellamy, M. Takase, K. Yamauchi, H. Wakabayashi, and K. Kawase. 1991. Potent antibacterial peptides generated by pepsin digestion of bovine lactoferrin. J. Dairy Sci. 74:4137-4142.

Vorland, L. H., H. Ulvatne, O. Rekdal, and J. S. Svendsen. 1999. Initial binding sites of antimicrobial peptides in Staphylococcus aureus and Escherichia coli. Scand. J. Infect. Dis. 31:467-473.

Wang, P., J. K. Bang, H. J. Kim, J. K. Kim, Y. Kim, and S. Y. Shin. 2009. Antimicrobial specificity and mechanism of action of disulfide-removed linear analogs of the plant-derived Cys-rich antimicrobial peptide Ib-AMP1. Peptides 30:2144-2149.

Wiegand, I., K. Hilpert, and R. E. Hancock. 2008. Agar and broth dilution methods to determine the minimal inhibitory concentration (MIC) of antimicrobial substances. Nat. Protoc. 3:163-175.

Wimley, W. C., and S. H. White. 2000. Determining the membrane topology of peptides by fluorescence quenching. Biochemistry 39:161-170.

Wu, M., and R. E. Hancock. 1999. Interaction of the cyclic antimicrobial cationic peptide bactenecin with the outer and cytoplasmic membrane. J. Biol. Chem. 274:29-35.

Wu, M., E. Maier, R. Benz, and R. E. Hancock. 1999. Mechanism of interaction of different classes of cationic antimicrobial peptides with planar bilayers and with the cytoplasmic membrane of Escherichia coli. Biochemistry 38:7235-7242.

Yamauchi, K., M. Tomita, T. J. Giehl, and R. T. Ellison 3rd. 1993. Antibacterial activity of lactoferrin and a pepsin-derived lactoferrin peptide fragment. Infect. Immun. 61:719-728.

Yeaman, M. R., N. Y. Yount, A. J. Waring, K. D. Gank, D. Kupferwasser, R. Wiese, A. S. Bayer, and W. H. Welch. 2007. Modular determinants of antimicrobial activity in platelet factor-4 family kinocidins. Biochim. Biophys. Acta 1768:609-619.

Zelezetsky, I., U. Pag, H. G. Sahl, and A. Tossi. 2005. Tuning the biological properties of amphipathic $\alpha$-helical antimicrobial peptides: Rational use of minimal amino acid substitutions. Peptides $26: 2368-2376$

Zelezetsky, I., and A. Tossi. 2006. Alpha-helical antimicrobial peptides - Using a sequence template to guide structure-activity relationship studies. Biochem. Biophys. Acta 1758(9):1436-1449.

Zhang, L., R. Benz, and R. E. Hancock. 1999. Influence of proline residues on the antibacterial and synergistic activities of $\alpha$-helical peptides. Biochemistry 38:8102-8111. 